Identification and Evaluation of Scientific Uncertainties Related to Fish and Aquatic Resources in the Colorado River, Grand Canyon-Summary and Interpretation of an Expert-Elicitation Questionnaire

Scientific Investigations Report 2013-5027 



\section{Identification and Evaluation of Scientific Uncertainties Related to Fish and Aquatic Resources in the Colorado River, Grand Canyon-Summary and Interpretation of an Expert-Elicitation Questionnaire}

By Theodore A. Kennedy

Scientific Investigations Report 2013-5027 


\section{U.S. Department of the Interior \\ KEN SALAZAR, Secretary}

\section{U.S. Geological Survey \\ Suzette M. Kimball, Acting Director}

U.S. Geological Survey, Reston, Virginia: 2013

For more information on the USGS - the Federal source for science about the Earth, its natural and living resources, natural hazards, and the environment—visit http://www.usgs.gov or call 1-888-ASK-USGS

For an overview of USGS information products, including maps, imagery, and publications, visit http://www.usgs.gov/pubprod

To order this and other USGS information products, visit http://store.usgs.gov

Any use of trade, firm, or product names is for descriptive purposes only and does not imply endorsement by the U.S. Government.

Although this information product, for the most part, is in the public domain, it also may contain copyrighted materials as noted in the text. Permission to reproduce copyrighted items must be secured from the copyright owner.

Suggested citation:

Kennedy, T.A., 2013, Identification and evaluation of scientific uncertainties related to fish and aquatic resources in the Colorado River, Grand Canyon-Summary and interpretation of an expert-elicitation questionnaire: U.S. Geological Survey Scientific Investigations Report 2013-5027, 34 p. 


\section{Contents}

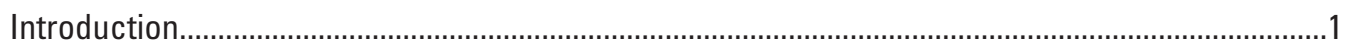

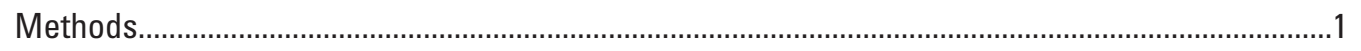

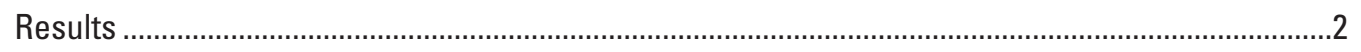

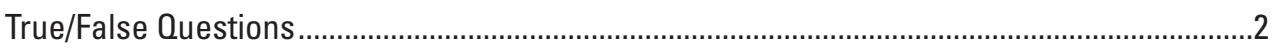

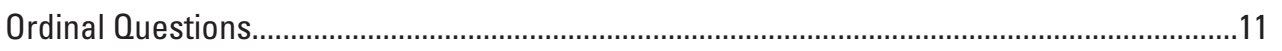

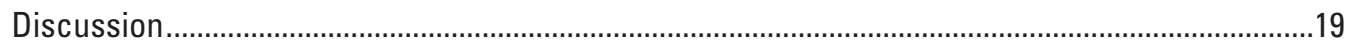

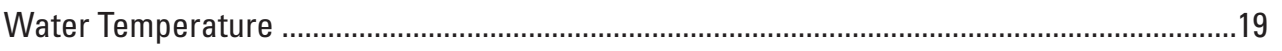

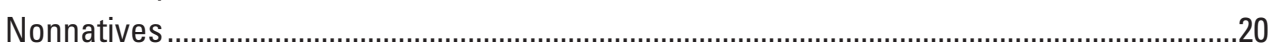

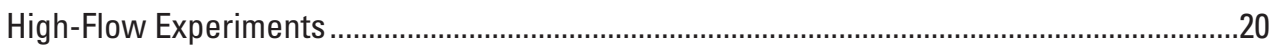

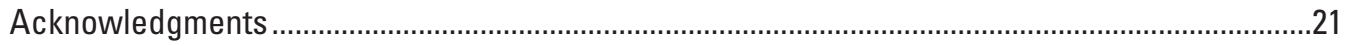

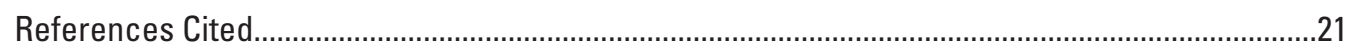

Appendix 1. Knowledge Assessment Workshop Questionnaire........................................................23

Appendix 2. Crosswalk between Original Strategic Science Questions (SSQs) and

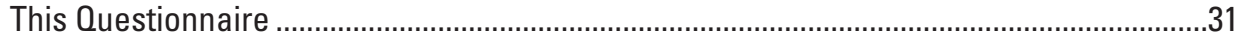

\section{Figures}

1. Bubble plots showing responses and confidence associated with true/false questions regarding the impact of four different nonnative taxa on juvenile

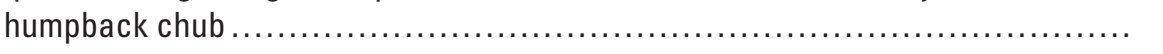

2. Bubble plot showing responses and confidence associated with a question regarding the interaction between fish populations and their food $\ldots \ldots \ldots \ldots \ldots . .7$

3. Bubble plot showing responses and confidence associated with a question regarding the influence of water quality on invertebrates $\ldots \ldots \ldots \ldots \ldots \ldots \ldots \ldots . . .6$

4. Bubble plots showing responses and confidence associated with questions regarding the effect of temperature and flow fluctuations on spawning and incubation success for native fish in the mainstem Colorado River ............. 9

5. Bubble plot showing responses and confidence associated with a question regarding the potential benefits of improving rearing habitat for native fish....... 10

6. Bubble plot showing responses and confidence associated with a question regarding downstream migration of rainbow trout from Glen Canyon ............ 11

7. Bubble plot showing responses and confidence associated with a question regarding the effects of turbidity on predation by nonnative species $\ldots \ldots \ldots \ldots \ldots 12$

8. Bubble plot showing responses and confidence associated with a question regarding effects of high-flow experiments on predation by nonnative fish ....... 13

9. Bubble plots showing answers and confidence associated with questions regarding potential benefits of backwaters and vegetated shorelines to native fish

10. Bubble plots showing answers and confidence associated with a question regarding native-fish response to implementation of a temperature-control device on Glen Canyon Dam, and the related true/false question asking whether safeguards are needed before a temperature control device can safely be operated

11. Bar graphs showing first, second, and third choice actions that respondents think should be conducted because of their potential to benefit native-fish populations 


\section{Tables}

1. Questions in the survey, answers given by respondents, confidence score associated with the question, rank of the confidence score, and associated figure number 


\title{
Identification and Evaluation of Scientific Uncertainties Related to Fish and Aquatic Resources in the Colorado River, Grand Canyon-Summary and Interpretation of an Expert-Elicitation Questionnaire
}

\author{
By Theodore A. Kennedy
}

\section{Introduction}

Identifying areas of scientific uncertainty is a critical step in the adaptive management process (Walters, 1986; Runge and others, 2011a). To identify key areas of scientific uncertainty regarding biological resources of importance to the Glen Canyon Dam Adaptive Management Program, the Grand Canyon Monitoring and Research Center (GCMRC) convened Knowledge Assessment Workshops in May and July 2005. One of the products of these workshops was a set of strategic science questions that highlighted key areas of scientific uncertainty. These questions were intended to frame and guide the research and monitoring activities conducted by the GCMRC in subsequent years. Questions were developed collaboratively by scientists and managers. The questions were not all of equal importance or merit-some questions were large scale and others were small scale. Nevertheless, these questions were adopted and have guided the research and monitoring efforts conducted by the GCMRC since 2005.

A new round of Knowledge Assessment Workshops was convened by the GCMRC in June and October 2011 and January 2012 to determine whether the research and monitoring activities conducted since 2005 had successfully answered some of the strategic science questions. Oral presentations by scientists highlighting research findings were a centerpiece of all three of the 2011-12 workshops. Each presenter was also asked to provide an answer to the strategic science questions that were specific to the presenter's research area. One limitation of this approach is that these answers represented the views of the handful of scientists who developed the presentations, and, as such, they did not incorporate other perspectives. Thus, the answers provided by presenters at the Knowledge Assessment Workshops may not have accurately captured the sentiments of the broader group of scientists involved in research and monitoring of the Colorado River in Glen and Grand Canyons. Yet a fundamental ingredient of resilient decisionmaking and problem-solving is the incorporation of a wide range of perspectives (Carpenter and others, 2009). To ensure that a wide range of scientists had an opportunity to weigh in on the strategic science questions, the GCMRC elicited additional perspectives through written questionnaires. Independently soliciting responses from scientists through questionnaires had the added advantage of allowing all scientists to freely and openly share their views on complex and controversial topics - something which may not have occurred in the group setting of the June 2011 Knowledge Assessment Workshop because of dominance by one or more scientists. The purpose of this report is to document and interpret the questionnaire responses.

\section{Methods}

Strategic science questions developed during the 2005 workshops were reworded so that answers were categorical. For each question, respondents also were asked to gauge their level of confidence in their answer on a four-point scale: very confident, confident, unconfident, and very unconfident. Two additional, open-ended questions also were developed to allow respondents to weigh in on management actions without the constraints inherent in the strategic science questions. 
Questionnaires that included 20 questions were distributed to 31 scientists and managers before the October 2011 workshop (see appendix 1 for a blank questionnaire). Questionnaires were provided to scientists who had been actively conducting research and monitoring in the Grand Canyon since the time of the 2005 workshops, including GCMRC scientists and cooperating scientists from Federal and State agencies, universities, and consulting firms. GCMRC managers who had been involved in scientific activities at a programmatic level also were provided the questionnaire. A total of 20 completed questionnaire were received - a 65-percent response rate.

Questions where respondents listed both true and false as answers on the same question were not coded. Ordinal questions where more than one categorical answer was checked were coded with the greater of the two scores. Five ranking questions were used on the survey, but the wording on these was apparently confusing, such that responses could not be accurately compiled; based on the notes that were provided by respondents, some individuals used a score of 1 for the highest ranked item in the list, others used larger numbers (that is, 5) to indicate highest ranked items, while still others ranked some items as ties. Responses to these ranking questions are omitted from this report (questions 2, 5, 7, 13, and 18 of the survey; see appendix 1).

Scoring on the confidence metric was as follows: very unconfident was scored as 0 , unconfident as 0.33 , confident as 0.67 , and very confident as 1 . Responses and associated confidence are here presented graphically, using bubble plots where the $x$-axis is the response, the $y$-axis is the associated confidence (from very unconfident to very confident), and the size of the bubble is proportional to the number of responses for a specific answer and confidence score. Questions also were ranked based on the basis of the average confidence score among all responses. Selected narratives that were written by scientists explaining, qualifying, or justifying their categorical, and necessarily simple, answers to extremely complex questions also are included in this report. Note that the narrative responses in this report are presented largely as written; minor punctuation was added in a few instances, and a few abbreviations or acronyms were defined or explained in brackets. Incomplete sentences and run-on sentences were retained to reflect the respondent's thinking. Responses to true/false questions are presented first, followed by responses to ordinal questions. Responses to one of the open-ended questions are presented next. This report concludes with a summary and interpretation of the survey responses on three key topics: water temperature, nonnative species, and highflow experiments.

\section{Results}

\section{True/False Questions}

Question 1A: If rainbow trout populations were large, a decrease in their abundance would lead to improvements in the recruitment of juvenile humpback chub to the adult population. True or False?

16 of 19 respondents (84 percent) answered True to this question, and 3 of 19 (16 percent) answered False (see fig. $1 A$ and table 1 ).

\section{Narratives Associated with True}

"This is only one factor potentially influencing juvenile [humpback chub] survival."

"There are likely other factors that influence [humpback chub] recruitment beyond simply [rainbow trout] abundance such as spawning and rearing habitat availability, carrying capacity/ density-dependence, temperatures, etc. Nevertheless, [rainbow trout] abundance is likely a factor in $\mathrm{HBC}$ [humpback chub] recruitment."

"If humpback chub thrive anywhere in the Grand Canyon, it is in the Little Colorado River; a river in which salmonids are very seldom captured. Virtually every other accessible tributary in Grand Canyon, including Shinumo and Havasu, contain rainbow trout as a common species. Like the [Little Colorado River], many of these other systems are warmwater systems, at least during parts of the year. Yet, humpback chub do not thrive in these systems. I have always been convinced that if the Little Colorado River were more amenable to rainbow trout, the humpback chub in Grand Canyon would be in very severe trouble."

\section{Narratives Associated with False}

"We have not shown the linkage yet; [it] appears that [humpback chub] are thriving in a period of high trout populations."

"Though [rainbow] trout piscivory is a factor, we have not definitively shown that their presence vs warmer water is a bigger lever on juvenile recruitment." 
Question 1. If (nonnative species $X$ ) populations were large, a decrease in their abundance would lead to improvements in recruitment of juvenile humpback chub to the adult population. True or false?

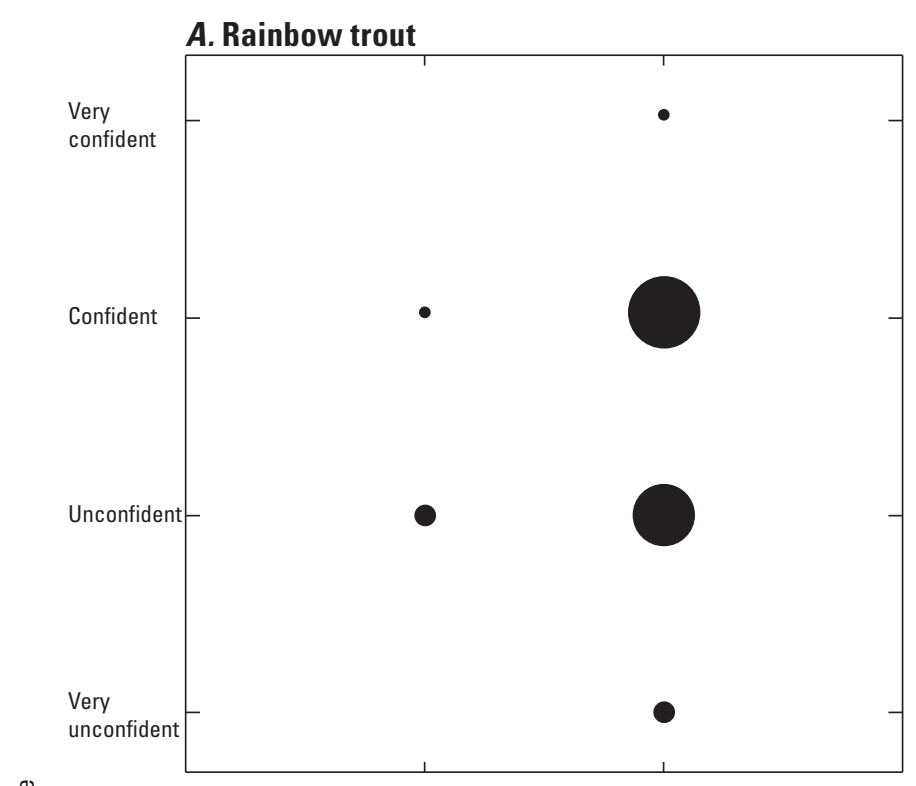

\section{B. Brown trout}

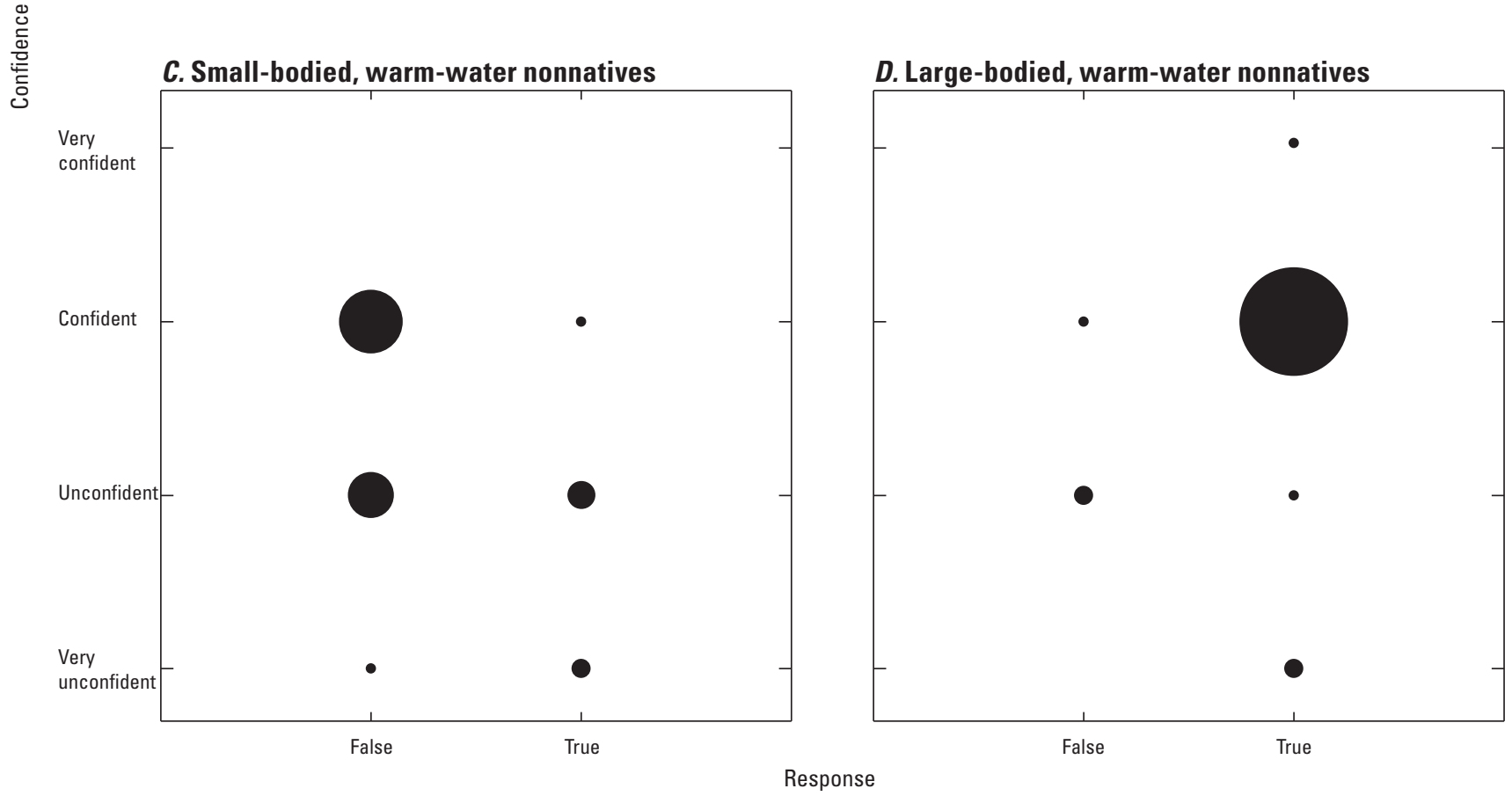

Figure 1. Responses and confidence associated with true/false questions regarding the impact of four different nonnative taxa on juvenile humpback chub $(A$, rainbow trout; $B$, brown trout; $C$, small-bodied, warm-water nonnatives, and $D$, large-bodied, warm-water nonnatives). Area of bubble is proportional to number of responses. Many respondents view brown trout as a threat to humpback chub populations relative to the number of respondents who view rainbow trout as a threat. Respondents actually view brown trout as a slightly greater threat to humpback chub than large-bodied, warm-water nonnatives, such as channel catfish. Respondents who view small-bodied, warm-water nonnatives (that is, red shiner, fathead minnow) as a threat to humpback chub are in the minority. (See table 1 for specific numbers.) 
Table 1. Questions in the survey, answers given by respondents, confidence score associated with the question, rank of the confidence score, and associated figure number.

\begin{tabular}{|c|c|c|c|c|c|}
\hline & Question number and question & $\begin{array}{c}\text { Tally of } \\
\text { answers }\end{array}$ & $\begin{array}{l}\text { Confi- } \\
\text { dence } \\
\text { score } \\
(0 \text { to } 1)\end{array}$ & $\begin{array}{l}\text { Confi- } \\
\text { dence } \\
\text { score } \\
\text { (rank) }\end{array}$ & $\begin{array}{l}\text { Related } \\
\text { figure } \\
\text { number }\end{array}$ \\
\hline $1 A$. & $\begin{array}{l}\text { If rainbow trout populations were large, a decrease in their } \\
\text { abundance would lead to improvements in the recruitment of } \\
\text { juvenile humpback chub to the adult population. }\end{array}$ & $\begin{array}{l}\text { 16-True } \\
\text { 3-False }\end{array}$ & 0.46 & 11 th & 1 \\
\hline $1 B$. & $\begin{array}{l}\text { If brown trout populations were large, a decrease in their } \\
\text { abundance would lead to improvements in the recruitment of } \\
\text { juvenile humpback chub to the adult population. }\end{array}$ & $\begin{array}{l}\text { 19-True } \\
1-\text { False }\end{array}$ & 0.58 & 6th & 1 \\
\hline $1 C$. & $\begin{array}{l}\text { If populations of small-bodied, warm-water nonnatives (that is, } \\
\text { fathead minnow, red shiner, etc.) were large, a decrease in their } \\
\text { abundance would lead to improvements in the recruitment of } \\
\text { juvenile humpback chub to the adult population. }\end{array}$ & $\begin{array}{c}\text { 6-True } \\
\text { 13-False }\end{array}$ & 0.42 & 13th & 1 \\
\hline $1 D$. & $\begin{array}{l}\text { If populations of large-bodied, warm-water nonnatives (that is, } \\
\text { channel catfish, common carp, etc.) were large, a decrease in } \\
\text { their abundance would lead to improvements in the recruitment } \\
\text { of juvenile humpback chub to the adult population. }\end{array}$ & $\begin{array}{l}\text { 16-True } \\
\text { 3-False }\end{array}$ & 0.56 & 8th & 1 \\
\hline 2. & $\begin{array}{l}\text { Are trends in the abundance of fish populations or indicators } \\
\text { from fish such as growth, condition, and body composition (for } \\
\text { example, lipids) correlated with patterns in invertebrate flux? In } \\
\text { other words, are fish food limited? }\end{array}$ & $\begin{array}{l}\text { 15-True } \\
\text { 2-False }\end{array}$ & 0.64 & 5 th & 2 \\
\hline 3. & $\begin{array}{l}\text { Is the amount of invertebrate biomass/production available for } \\
\text { consumption by fish affected by water quality parameters (for } \\
\text { example, temperature, nutrient concentrations, turbidity)? }\end{array}$ & $\begin{array}{l}\text { 19-True } \\
1-\text { False }\end{array}$ & 0.81 & 1 st & 3 \\
\hline 4. & $\begin{array}{l}\text { Do current water temperatures limit spawning and incubation } \\
\text { success for native fish in the mainstem? }\end{array}$ & $\begin{array}{l}\text { 18-True } \\
1-\text { False }\end{array}$ & 0.79 & 2nd & 4 \\
\hline 5. & $\begin{array}{l}\text { Do current flow fluctuations allowed by the Record of Decision } \\
\text { (that is, MLFF) limit spawning and incubation success for native } \\
\text { fish in the mainstem? }\end{array}$ & $\begin{array}{l}\text { 3-True } \\
\text { 14-False }\end{array}$ & 0.57 & 7 th & 4 \\
\hline 6. & $\begin{array}{l}\text { Do the potential benefits of improving juvenile native fish- } \\
\text { rearing habitat in the mainstem (for example, increasing water } \\
\text { temperatures with a TCD, stabilizing flows, conducting frequent } \\
\text { HFEs to increase the number of backwater and vegetated } \\
\text { shorelines) outweigh negative impacts due to increases in } \\
\text { nonnative fish. }\end{array}$ & $\begin{array}{l}\text { 12-True } \\
\text { 3-False }\end{array}$ & 0.46 & 12 th & 5 \\
\hline 7. & $\begin{array}{l}\text { To what extent do rainbow trout migrating from Glen Canyon } \\
\text { support the population of rainbow trout in Marble and eastern } \\
\text { Grand Canyon? } \\
\text { Choices: 'Does not support', 'Partially Supports', 'Largely } \\
\text { Supports', and 'Completely Supports'' }\end{array}$ & $\begin{array}{l}\text { 2-'Partially Supports' } \\
\text { 18-'Largely Supports' }\end{array}$ & 0.73 & $3 \mathrm{rd}$ & 6 \\
\hline 8. & To what extent could predation impacts by nonnative fish be & 3-'Greatly Decrease Predation' & 0.52 & 10 th & 7 \\
\hline
\end{tabular}
mitigated by higher turbidities? Higher turbidity would impacts by nonnatives.

Choices: 'Greatly Increase Predation', 'Somewhat increase predation', 'No Impact on Predation', 'Somewhat Decrease Predation', 'Greatly Decrease Predation' 
Table 1. Questions in the survey, answers given by respondents, confidence score associated with the question, rank of the confidence score, and associated figure number.-Continued

\begin{tabular}{|c|c|c|c|c|c|}
\hline & Question number and question & $\begin{array}{c}\text { Tally of } \\
\text { answers }\end{array}$ & $\begin{array}{l}\text { Confi- } \\
\text { dence } \\
\text { score }\end{array}$ & $\begin{array}{l}\text { Confi- } \\
\text { dence } \\
\text { score }\end{array}$ & $\begin{array}{l}\text { Related } \\
\text { figure }\end{array}$ \\
\hline 9. & $\begin{array}{l}\text { To what extent could predation impacts by nonnative fish be } \\
\text { mitigated by dam-controlled high-flow releases? Frequent high- } \\
\text { flow experiments would_ by nonnatives. } \\
\text { Choices: 'Greatly Increase Predation', 'Somewhat Increase } \\
\text { Predation', 'No Impact on Predation', 'Somewhat Decrease } \\
\text { Predation', 'Greatly Decrease Predation' }\end{array}$ & $\begin{array}{l}\text { 1-'Greatly Increase Predation' } \\
\text { 6-'Somewhat Increase Predation } \\
\text { 5-'No Impact on Predation' } \\
\text { 5-'Somewhat Decrease Predation' }\end{array}$ & 0.40 & 14th & 8 \\
\hline 10. & $\begin{array}{l}\text { An increase in the size, distribution, and number of backwaters } \\
\text { would cause a in native fish abundance. } \\
\text { Choices: 'Substantial Decrease', 'Decrease', 'No } \\
\text { Change', 'Increase', 'Substantial Increase' }\end{array}$ & $\begin{array}{l}\text { 1-'Decrease' } \\
\text { 11-'No Change' } \\
\text { 7-'Increase' }\end{array}$ & 0.36 & 16th & 9 \\
\hline 11. & $\begin{array}{l}\text { An increase in the size, distribution, and number of vegetated } \\
\text { shorelines would cause a in native fish abundance. } \\
\text { Choices: 'Substantial Decrease', 'Decrease', 'No Change', } \\
\text { Increase', 'Substantial Increase'. }\end{array}$ & $\begin{array}{l}\text { 11-'No Change' } \\
\text { 7-'Increase' }\end{array}$ & 0.39 & 15 th & 9 \\
\hline & $\begin{array}{l}\text { What will happen if a temperature control device is } \\
\text { implemented? } \\
\text { Native fish abundance will } \\
\text { Choices: 'Substantially Decrease', 'Decrease', 'No Change', } \\
\text { 'Increase', 'Substantially Increase' }\end{array}$ & $\begin{array}{l}\text { 1-'Substantially Decrease' } \\
\text { 13-'Increase' } \\
\text { 4-'Substantially Increase' }\end{array}$ & 0.53 & 9th & 10 \\
\hline & $\begin{array}{l}\text { Are safeguards needed before a temperature control device can } \\
\text { aafely be operated? }\end{array}$ & $\begin{array}{l}\text { 13-True } \\
2-\text { False }\end{array}$ & 0.68 & 4 th & 10 \\
\hline
\end{tabular}

Question 1B: If brown trout populations were large, a decrease in their abundance would lead to improvements in the recruitment of juvenile humpback chub to the adult population. True or False?

19 of 20 respondents (95 percent) answered True, and 1 of 20 (5 percent) answered False (see fig. 1B; table 1).

\section{Narratives Associated with True}

"This is only one factor potentially influencing juvenile [humpback chub] survival."

"We have data to indicate brown trout are highly piscivourous, but whether or not they can cause changes in [adult humpback chub] populations is unknown, [and] all data from other systems indicate that brown trout could have large population level effects."

"Of all the aggregations of humpback chub in Grand Canyon, it is most rare to capture a humpback chub in the Bright Angel aggregation. This is despite some historical information that the species may have been very common in this reach of river (type locality specimens, and at least one early pre-dam photograph of a stringer of large humpback chub angled during a leisurely afternoon near Roy's Beach, I believe). Although some may dismiss these as anecdotal records, it does suggest that humpback chub were occasionally, if not always, a common species near Bright Angel Creek."

"Brown [trout] are very piscivorous..."

\section{Narratives Associated with False}

"Maybe, maybe not. There are a lot of factors affecting recruitment of chub to adults, including temperature, interactions with nonnatives, conditions in the Little Colorado River (likely including density dependent survival). Relieving one of those pressures would not necessarily lead to improvements in recruitment of [humpback chub]." 
Question 1C: If populations of small-bodied, warm-water nonnatives (that is, fathead minnow, red shiner, etc.) were large, a decrease in their abundance would lead to improvements in the recruitment of juvenile humpback chub to the adult population. True or False?

13 of 19 respondents (68 percent) answered False, and 6 of 19 (32 percent) answered True (fig. 1C; table 1).

\section{Narratives Associated with True}

"I do not feel that we know very much about these species and their interactions with HBC."

"I am hard pressed to say that any non-native occupying similar niches [as humpback chub] would not have an effect on juvenile [humpback chub] recruitment."

\section{Narratives Associated with False}

"I do not think these species compete with humpback chub. If anything, I think adult humpback chub eat these small-bodied nonnatives."

"The only small-bodied non-native that I would be worried about in high densities is plains killifish, as they are highly predatory. They are relatively rare, fortunately. I do not think the pressure from competition is nearly as important as predation."

"I really do not believe that small-bodied fishes are the limiting factor of humpback chub in the Colorado River. If they were, then they should be much more abundant in the Little Colorado River and near its confluence in the Colorado River."

"Fatheads and red shiners currently pose no real numerical threat in my opinion."

“...juvenile and adult humpback chub likely prey on fatheads."

Question 1D: If populations of large-bodied, warm-water nonnatives (that is, channel catfish, common carp etc.) were large, a decrease in their abundance would lead to improvements in the recruitment of juvenile humpback chub to the adult population. True or False?

16 of 19 respondents (84 percent) answered True, and 3 of 19 (16 percent) answered False (fig. 1D; table 1).

\section{Narratives Associated with True}

"This is a good question with terrible examples. Carp and catfish have been present in the Colorado River for $75+$ years, and these large-bodied warm water species are likely not the ones to worry about the most. Piscivorous warm-water species like smallmouth bass, flathead catfish, and striped bass are more worrisome."

"It depends on the species, channel catfish are longlived piscivores that would likely impact recruitment of juvenile HBC."

"Catfish are big time predators..."

\section{Narratives Associated with False}

"I think a decrease in abundance of channel catfish in the [Little Colorado River] would lead to improvements in juvenile humpback chub survival in the [Little Colorado River], but whether that would lead to increased recruitment to adults is unknown. Again, [we] do not know where the bottleneck is..."

"It is hard to say with much confidence how carp or catfish influence [humpback chub] recruitment since they may be also somewhat limited by cold temperatures presently."

Question 2: Trends in the abundance of fish populations or indicators from fish, such as growth, condition, and body composition (for example, lipids), are correlated with patterns in invertebrate flux-in other words, fish are food limited. True or False?

15 of 17 respondents (88 percent) answered True, and 2 of 17 (12 percent) answered False (fig. 2; table 1). Several respondents felt this was a poorly worded question because there were actually two questions being asked. In general, respondents believed there is strong evidence that rainbow trout populations are food limited. Several respondents also described observations from their field efforts indicating that humpback chub in the Little Colorado River were, at times, food limited.

\section{Narratives Associated with True}

"If you look at the [rainbow] trout, then yes they are food limited. If you look at the adult humpback chub, they seem quite robust and do not seem food-limited." 
“...if you are talking about rainbow trout at Lee's Ferry, Korman's research demonstrates that higher food abundances $=$ higher trout abundance (for example, after experimental floods). So they are experiencing some food limitation. Are brown trout near Phantom Ranch food-limited? I do not think so; lots of fish to eat, both native and nonnative. Are rainbow trout below the Little Colorado River food-limited? At least some of the time, based on poor conditions we observed in trout [in 2011]. Humpback chub do not seem to be food-limited based on observed condition, but that is a data[poor] area."

"Downstream fish demand [for invertebrates] is close to invertebrate production..."

"Good empirical evidence of this for rainbow trout in Lees Ferry and Marble Canyon..."

\section{Narratives Associated with False}

"Fish may be food-limited in the Little Colorado River, but likely not in the mainstem."

"Unknown, but if native fish were truly food-limited in the mainstem under current operating regimes, would not we expect to at least occasionally see strikingly poor condition factors en masse in native fish, which we do not. On the other hand, I have witnessed strikingly poor condition factors of age-1 humpback chub in the Little Colorado River (skinny with ribs poking through their sides) during the early 1990s. This suggests to me that while the Little Colorado River can be food-limited, the mainstem is not."

Question 2: Are trends in the abundance of fish populations or indicators from fish such as growth, condition, and body composition (for example, lipids), correlated with patterns in invertebrate flux? In other words, are fish food-limited?

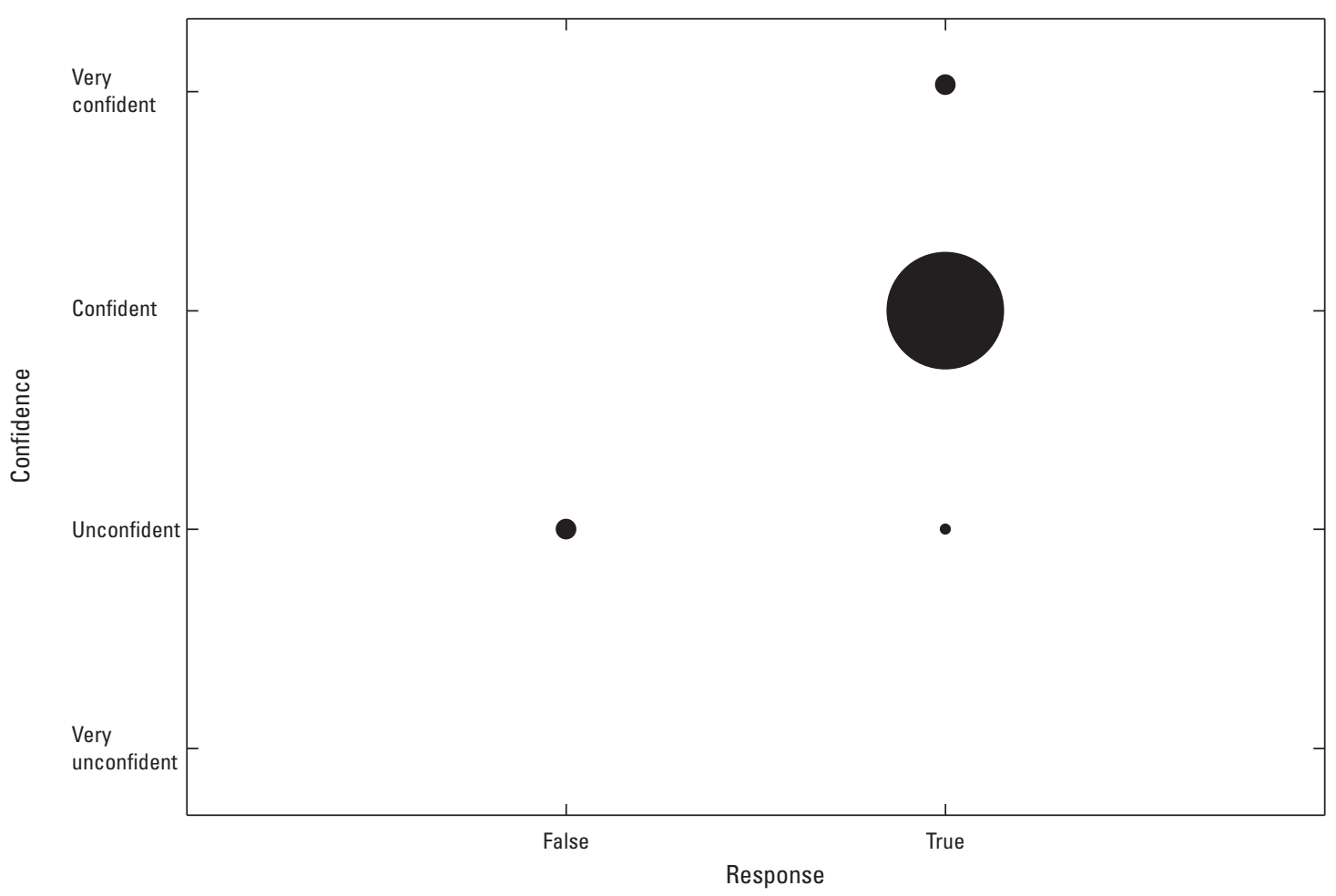

Figure 2. Responses and confidence associated with a question regarding the interaction between fish populations and their food. Invertebrate flux is a term used to represent both the quantity and concentration of invertebrate available as food in the drift. Area of bubble is proportional to number of responses. Some respondents noted that this was a poorly worded question because there were actually two questions being asked. Nevertheless, a large number of respondents feel there is sufficient evidence to conclude that fish in the Colorado River are food-limited. 
Question 3: The amount of invertebrate biomass/production available for consumption by fish is affected by waterquality parameters (for example, temperature, nutrient concentrations, turbidity: True or False?

19 of 20 respondents (95 percent) answered True, and 1 of 20 (5 percent) answered False (fig. 3; table 1).

\section{Narratives Associated with True}

"Bug production 101. But I note that it is not water quality per se, but rather the supply or organic carbon which is related to nutrients, turbidity, hydrology, etc."

"Based on data collected in rivers around the world, we are very certain that these factors influence invertebrate production."
Question 4: Current water temperatures limit spawning and incubation success for native fish in the mainstem: True or False?

18 of 19 respondents ( 95 percent) answered True, and 1 of 19 (5 percent) answered False (fig. 4A; table 1).

\section{Narratives Associated with True}

"Read the literature. Witness the situation."

"Yes for some species and in some locations."

"This is supported by miscellaneous research publications by Roger Hamman, and others."

Narratives Associated with False

"I do think that rearing of larvae and juveniles is impacted by the cold water."

Question 3: Is the amount of invertebrate biomass/production available for consumption by fish affected by water-quality parameters (for example, temperature, nutrient concentrations, turbidity)?

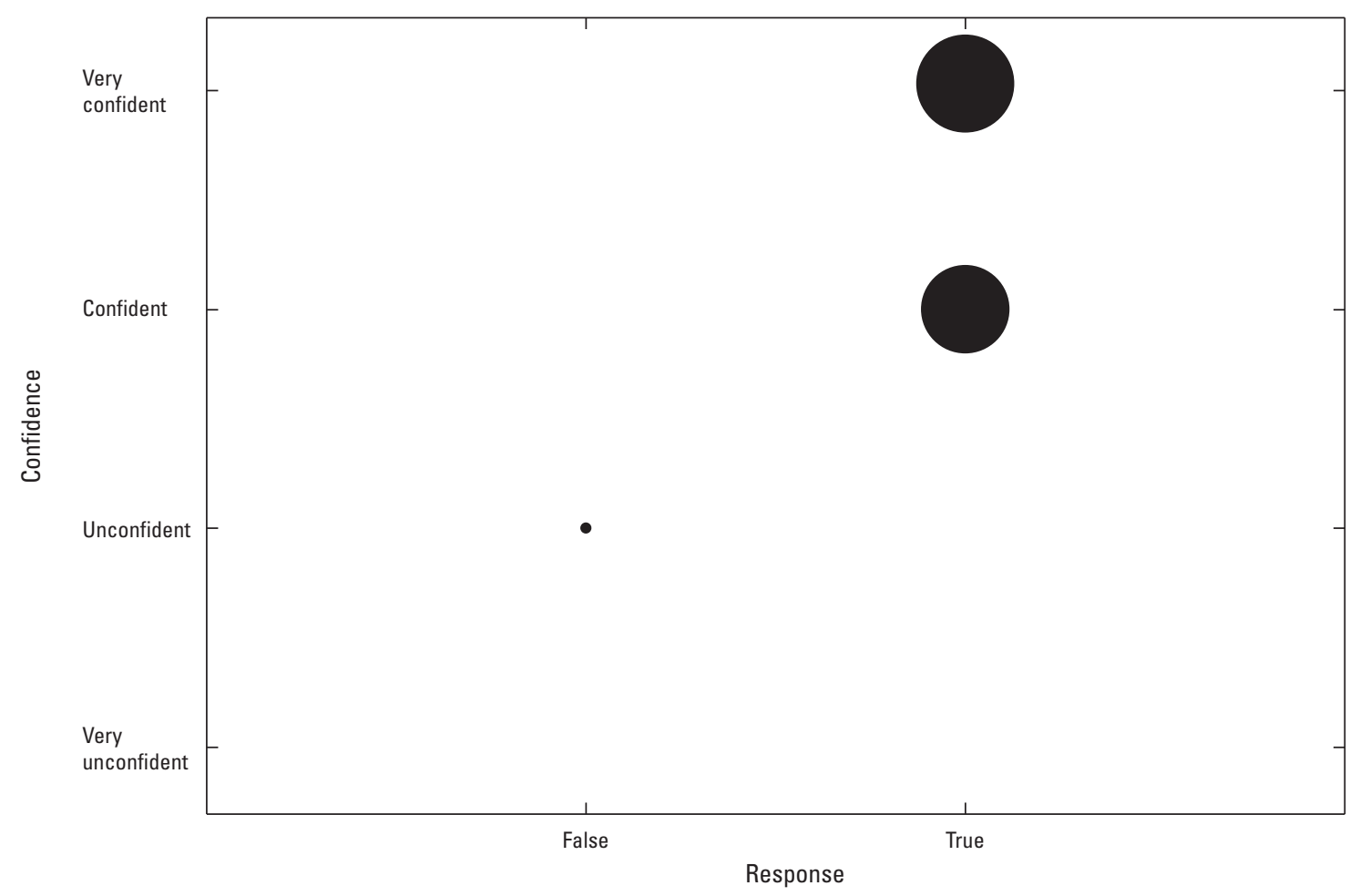

Figure 3. Responses and confidence associated with a question regarding the influence of water quality on invertebrates. Area of the bubble is proportional to the number of responses. This question had the highest confidence score in the survey. 
Question 5: Do current flow fluctuations allowed by the Record of Decision (that is, Modified Low Fluctuating Flows) limit spawning and incubation success for native fish in the mainstem. True or False?

3 of 14 respondents (21 percent) answered True, and 11 of 14 (79 percent) answered False (fig. 4B; table 1).

\section{Narratives Associated with True}

"There is likely an interactive effect of flows, temperatures, and nonnative fish abundance upon native fish recruitment."

"Yes, when coupled with cold mainstem water temperatures. If not, then I do not think it much

Question 4. Do current water temperatures limit spawning and incubation success for native fish in the mainstem?

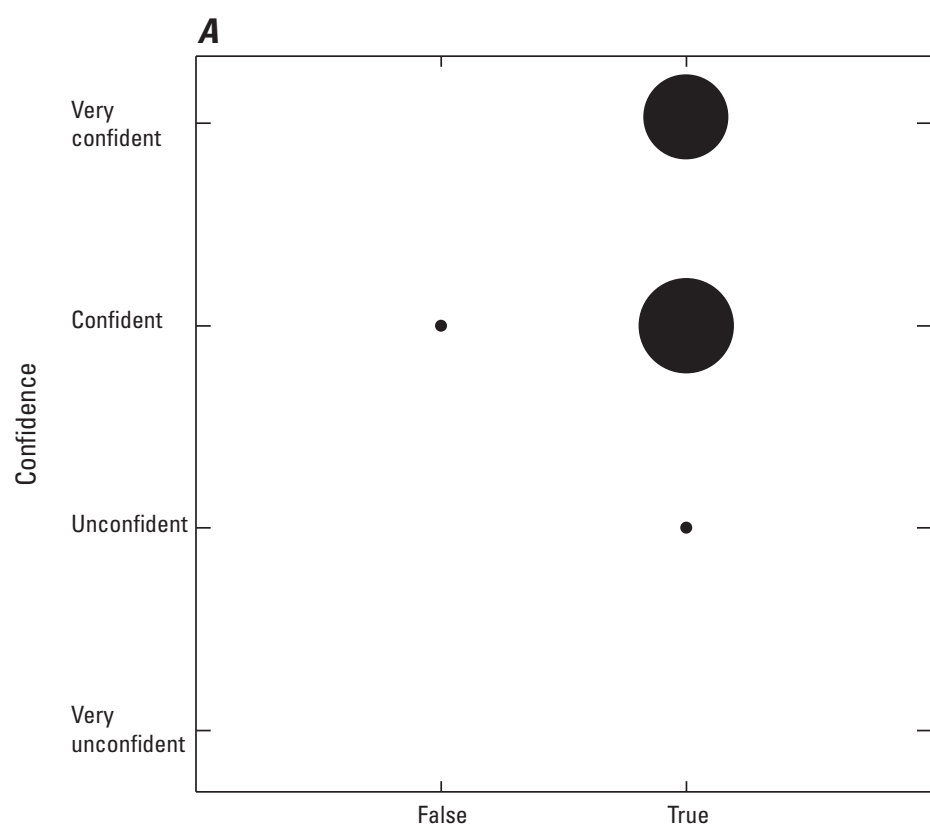

matters. Chub spawn and recruit from year to year in the Little Colorado River under varying flow conditions."

\section{Narratives Associated with False}

"The small fluctuations in flow are not the principal problem."

"The flows currently have little effect on temperature and temperature is the overriding factor for spawning and incubation success."

"Maybe to a degree, but I believe water temperature is the most limiting factor. The effects of daily fluctuations in discharge become more reduced at farther downriver distances from the dam."

Question 5. Do current flow fluctuations allowed by the Record of Decision (that is, MLFF) limit spawning and incubation success for native fish in the mainstem?

\section{B}

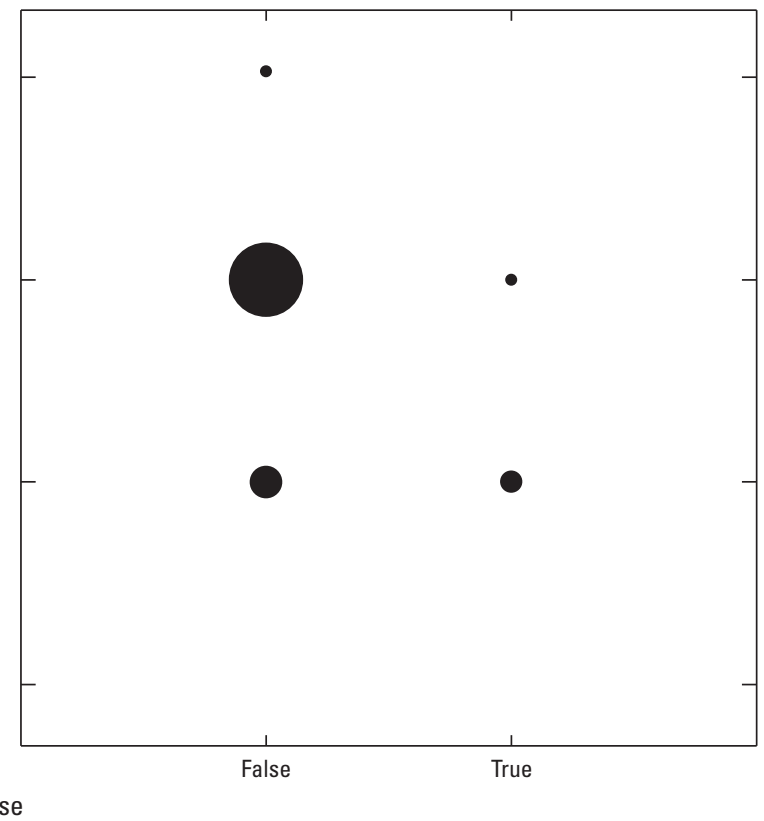

Figure 4. Responses and confidence associated with questions regarding the effect of temperature $(A)$ and flow fluctuations $(B)$ on spawning and incubation success for native fish in the mainstem Colorado River. Area of the bubble is proportional to the number of responses. There is wide agreement among respondents that water temperatures limit spawning and incubation success for native fish in the mainstem $(A)$. In contrast, more respondents surveyed believe that flow fluctuations do not limit spawning and incubation success for native fish in the mainstem $(B)$. 
Question 6: The potential benefits of improving juvenile native fish rearing habitat in the mainstem (for example, increasing water temperatures with a [temperature-control device], stabilizing flows, conducting frequent HFEs (highflow experiments) to increase the number of backwater and vegetated shorelines) outweigh negative impacts due to increases in nonnative fish. True or False?

12 of 15 respondents ( 80 percent) answered True, and 3 of 15 (20 percent) answered False (fig. 5; table 1).

\section{Narratives Associated with True}

" One would assume so, but some level of predator control may still be necessary. Nonnative fish are still a primary threat."

"Some actions like warming the water, I am confident, will have a positive impact on native fish; others like [high flow experiments] and backwaters, I am less convinced, will have a positive impact."
"I think we have to assume this to be true."

\section{Narratives Associated with False}

"It is likely that these actions will fail, but not absolutely certain. We can find this out with some adaptive management experimentation, but the risks are high. I am not sure it is worth it since the current humpback chub population is stable or increasing, and it almost certainly would not be if the river warmed up and nonnative predators proliferated."

"Using the Upper Basin as a case study, which has more natural flow and temperature regimes but an abundance of warm-water nonnatives and low recruitment for some natives, it is likely some form of nonnative fish control would be necessary along with improvements to native fish habitat to result in a benefit to native fish over the long term."

Question 6: Do the potential benefits of improving juvenile native fish-rearing habitat in the mainstem (for example, increasing water temperatures with a TCD, stabilizing flows, conducting frequent HFEs to increase the number of backwaters and vegetated shorelines, increasing food availability) outweigh negative impacts due to increases in nonnative fish?

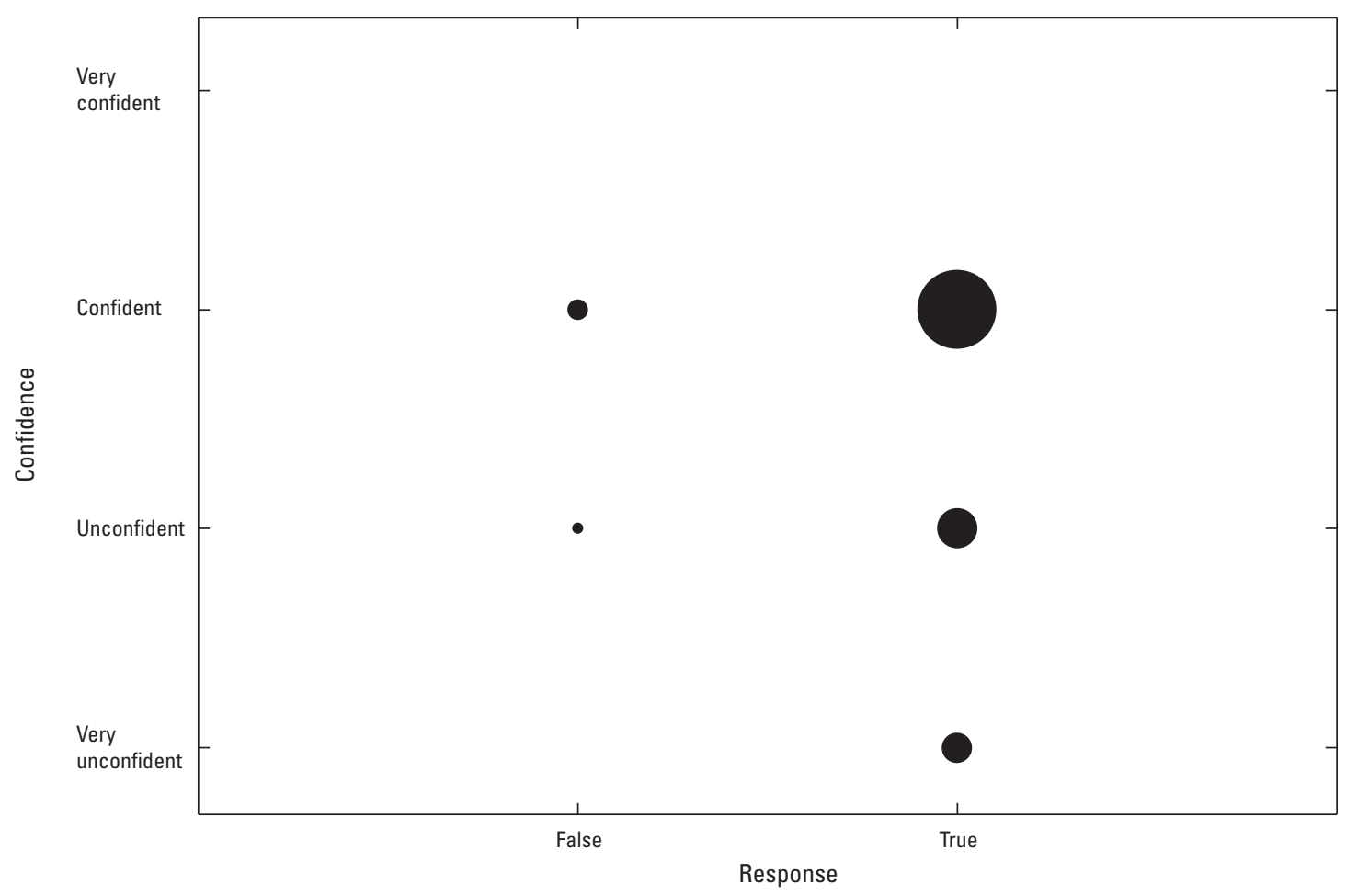

Figure 5. Responses and confidence associated with a question regarding the potential benefits of improving rearing habitat for native fish. Area of the bubble is proportional to the number of responses. Most respondents believe that improving the quality of juvenile native fish rearing habitat outweighs potential negative impacts of such habitat improvements due to increase in nonnatives. 


\section{Ordinal Questions}

Question 7: To what extent do rainbow trout migrating from Glen Canyon support the population of rainbow trout in Marble and eastern Grand Canyons? Migration from Glen Canyon populations in Marble and Grand Canyon.

Choices: Does not support, Partially Supports, Largely Supports, Completely Supports.

18 of 20 respondents (90 percent) answered Largely Supports, and 2 of 20 (10 percent) answered Partially Supports (fig. 6; table 1).

\section{Narratives}

"It depends. During periods of high trout density in Glen Canyon, I assume that downstream movement supports rbt [rainbow trout] between the Paria and LCR, assuming turbidity is not a big issue limiting their growth and survival. During periods of low density in Glen Canyon, they likely do not support rbt populations between the Paria and LCR. During the late 1980s and early 1990s when the Glen Canyon fishery was supported by stocking (little to no natural recruitment), all hatchery stocked fingerlings were marked with coded wire tags. [There was] no evidence of movement of those fish, granted sampling was more limited downstream."

"Lees Ferry is a density-dependent food-limited system, and thus fish probably migrate downstream over time. The age and timing of migrants is unclear. There are likely other suitable spawning locations for rainbows downstream, and this should not be completely overlooked."

Question 7: To what extent do rainbow trout migrating from Glen Canyon support the population of rainbow trout in Marble and eastern Grand Canyon?

Migration from Glen Canyon populations in Marble and Grand Canyon.

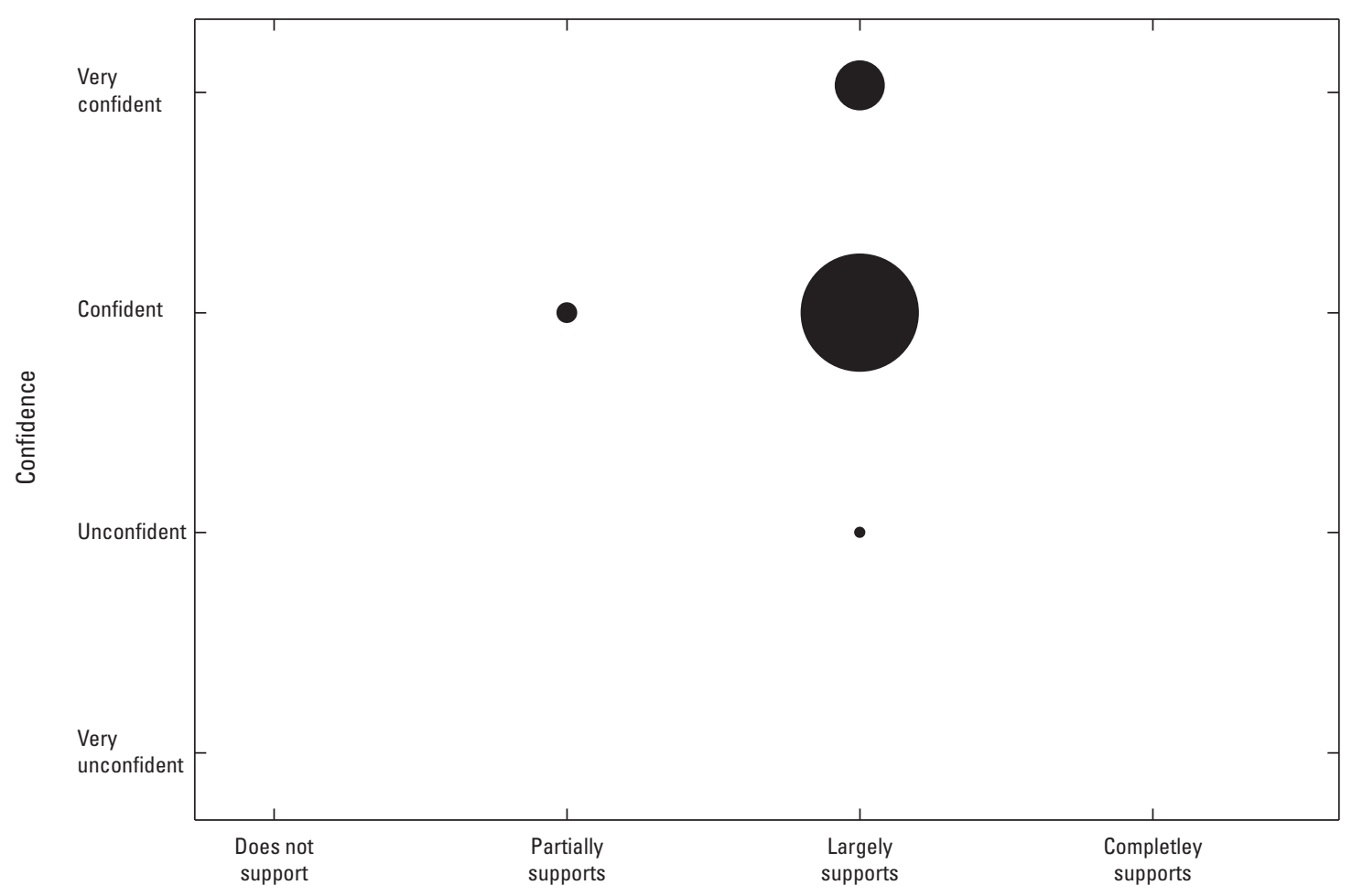

Figure 6. Responses and confidence associated with a question regarding downstream migration of rainbow trout from Glen Canyon. Area of bubble is proportional to number of responses. A majority of respondents believe there is sufficient evidence to conclude that migration of rainbow trout from Glen Canyon largely supports the rainbow trout populations present in Marble and eastern Grand Canyon. 
Question 8: To what extent could predation impacts by nonnative fish be mitigated by higher turbidities? Higher turbidity would impacts by nonnatives.

Choices: Greatly Increase Predation, Somewhat Increase Predation, No Impact on Predation, Somewhat Decrease Predation, Greatly Decrease Predation.

14 of 17 respondents (82 percent) answered Somewhat Decrease Predation, and 3 of 17 (18 percent) answered Greatly Decrease Predation (fig. 7; table 1).

\section{Narratives}

"If higher turbidity persisted for long enough...there is a temporal and seasonal element here."
"Depends on the nonnative. If they are a visual predator like rainbow trout, then the predation impacts could likely be mitigated."

"There are gobs of peer-reviewed publications affiliated with this topic. Overall, this depends on the non-visual capabilities of the predators versus those of native fishes. For example, channel catfish function much better under high turbidities than rainbow trout."

"Many of the predators in the canyon are sightfeeders, so I suspect predation overall would go down. However, certain species (channel catfish, possibly walleye in the future) are well adapted to low-light conditions, so predation by these species may remain stable or increase."

Question 8: To what extent could predation impacts by nonnative fish be mitigated by higher turbidities?

Higher turbidity would __-__-_-__-___ impacts by nonnatives.

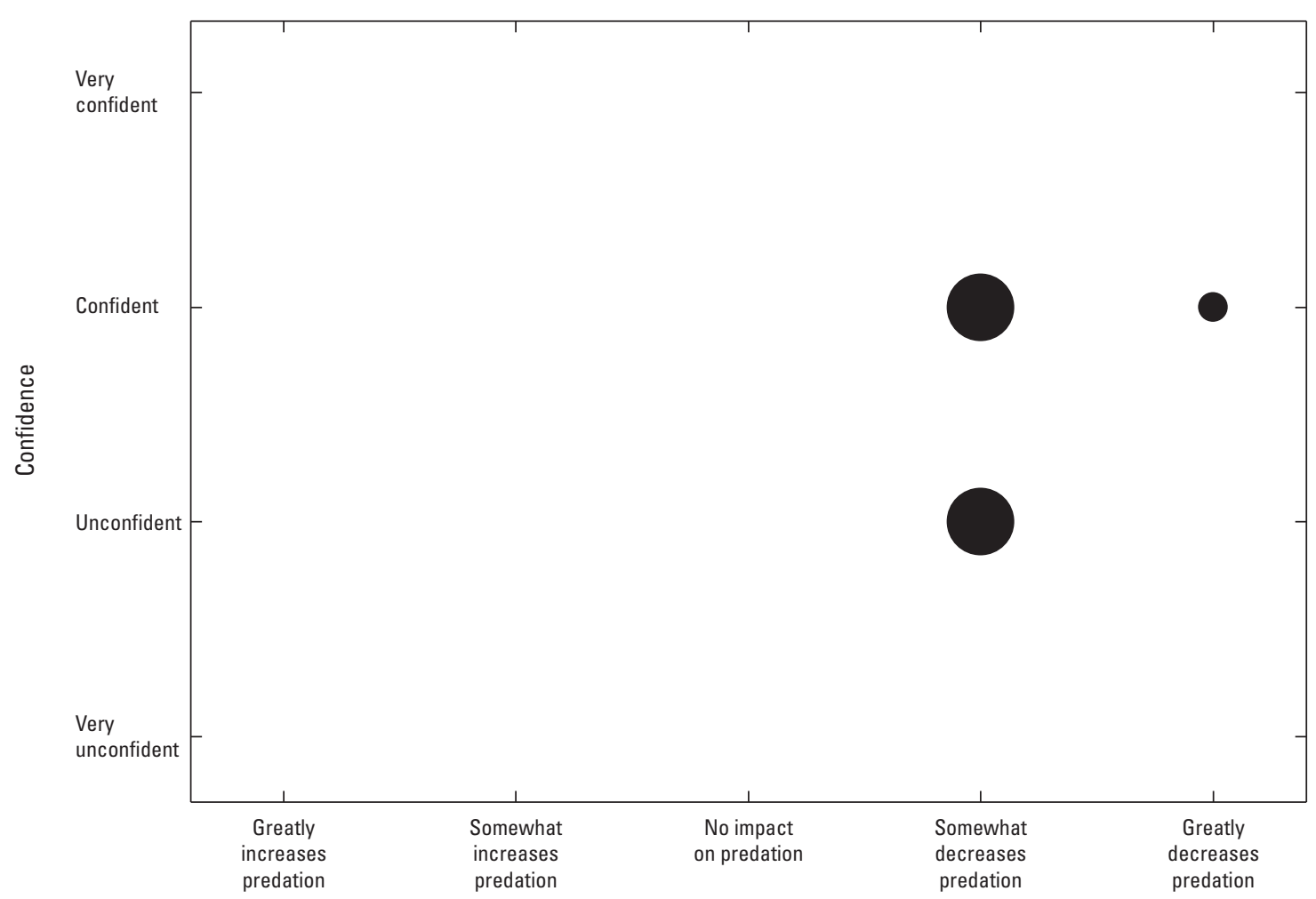

Figure 7. Responses and confidence associated with a question regarding the effects of turbidity on predation by nonnative species. Area of bubble is proportional to the number of responses. Most respondents believe that higher turbidity would Somewhat Decrease Predation of native fishes. 
Question 9: To what extent could predation impacts by nonnative fish be mitigated by dam-controlled high-flow releases? Frequent high-flow experiments would by nonnatives.

Choices: Greatly Increase Predation, Somewhat Increase Predation, No Impact on Predation, Somewhat Decrease Predation, Greatly Decrease Predation.

No single answer received a majority of responses (fig. 8; table 1); 6 of 17 respondents (35 percent) answered Somewhat Increase Predation; 5 of 17 respondents (29 percent) answered No Impact on Predation; and 5 of 17 answered Somewhat Decrease Predation.

\section{Narratives}

"I assume that this question is geared toward [rainbow trout]? If so then the timing of the floods would have to be critical as to not increase trout recruitment. Would have to be done in conjunction with low flows."
"If the high flow releases were large enough to disproportionately displace nonnative fish (which they usually are not), then predation would be reduced."

"It is my expectation that HFEs would [cleanse] salmonid spawning redd habitat, and contribute to higher production of rainbow trout. I do not think that this increase in salmonid abundance (and presumably emigration rates downriver) would be offset by any potential positive aspects of creation of backwaters, particularly if ensuing fluctuating flows render backwaters of limited utility and duration."

"The answer to this question appears to be dependent on the timing of flows, the magnitude, etc. Flows could be designed to maintain lower densities of RBT by discouraging recruitment possibly, however high flows could also result in dramatic increases in RBT recruitment...."

Question 9: To what extent could predation impacts by nonnative fish be mitigated by dam-controlled high-flow releases? Frequent high-flow experiments would by nonnatives.

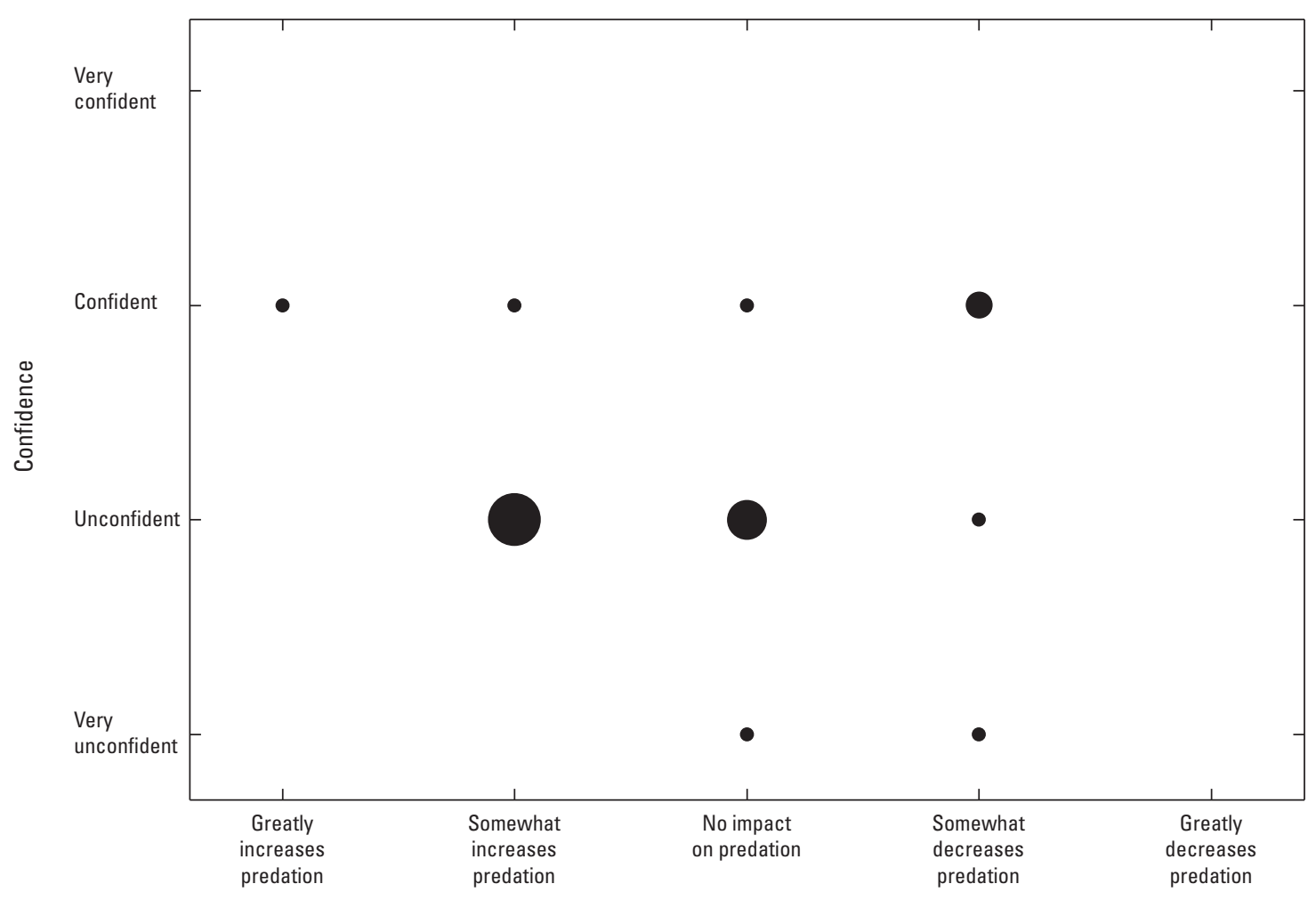

Figure 8. Responses and confidence associated with a question regarding effects of high-flow experiments on predation by nonnative fish. Area of the bubble is proportional to the number of responses. Respondents do not believe that high-flow releases are a useful tool for decreasing predation of native fishes. 
Question 10: An increase in the size, distribution, and number of backwaters would cause a in native fish abundance.

Choices: Substantial Decrease, Decrease, No Change, Increase, Substantial Increase.

Most respondents (11 of 19, or 58 percent) answered No Change in native fish abundance as the most likely outcome of an increase in backwaters (fig. 9A; table 1).

\section{Narratives}

"Hard to answer this without knowing what 'increase' means. Unless [backwaters] became a substantial part of the mainstem habitat, an 'increase' would do little."

Question 10: An increase in the size, distribution, and number of backwaters would cause a in native fish abundance.

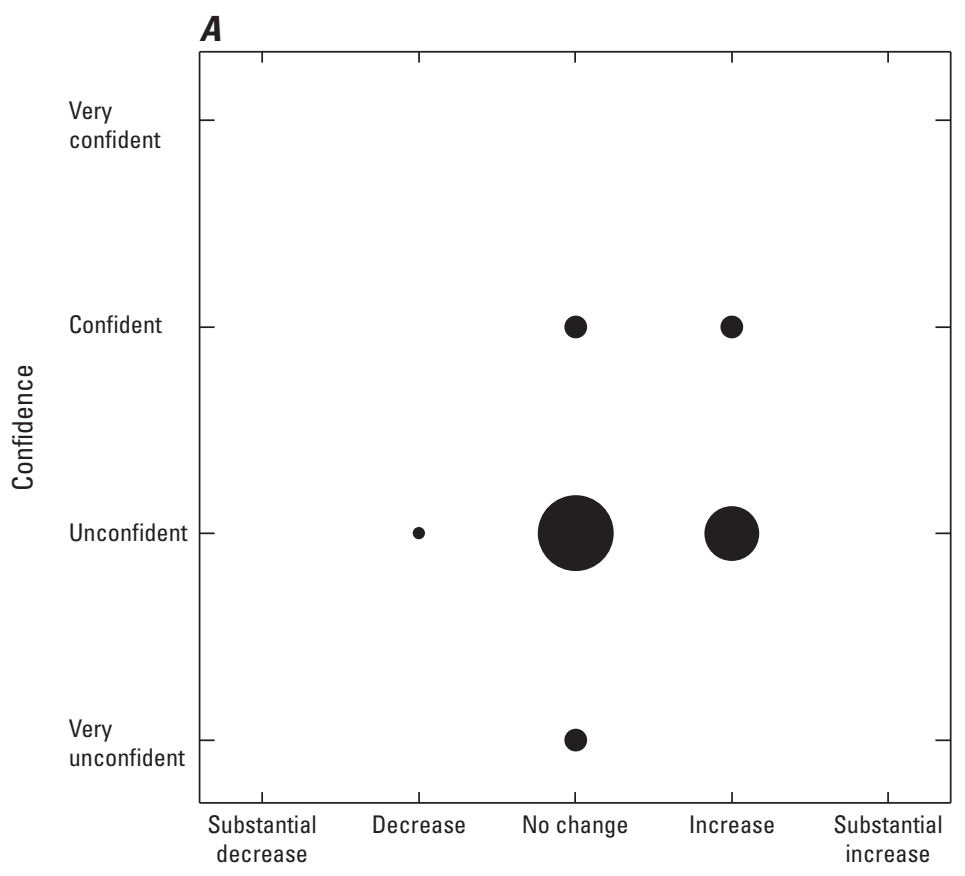

"I see no reason that native fish would respond better than nonnative fish due to increased backwater availability. The abundance of warm-water fish will increase system-wide, regardless of species. Also, I think persistence of backwaters is just as important as these other factors, both on diel and seasonal scales. We need a high flow event followed by a steady flow event if you want to create and maintain backwaters long enough to have an effect on warmwater fish."

"[If backwater does not persist], even the best scenario for backwaters is of likely of limited use as significant thermal refugia. With stable flows, many backwaters should be expected to provide some opportunities for increased growth for a fraction of the small size classes of native fishes in the

Question 11: An increase in the size, distribution, and number of vegetated shorelines would cause a in native fish abundance.

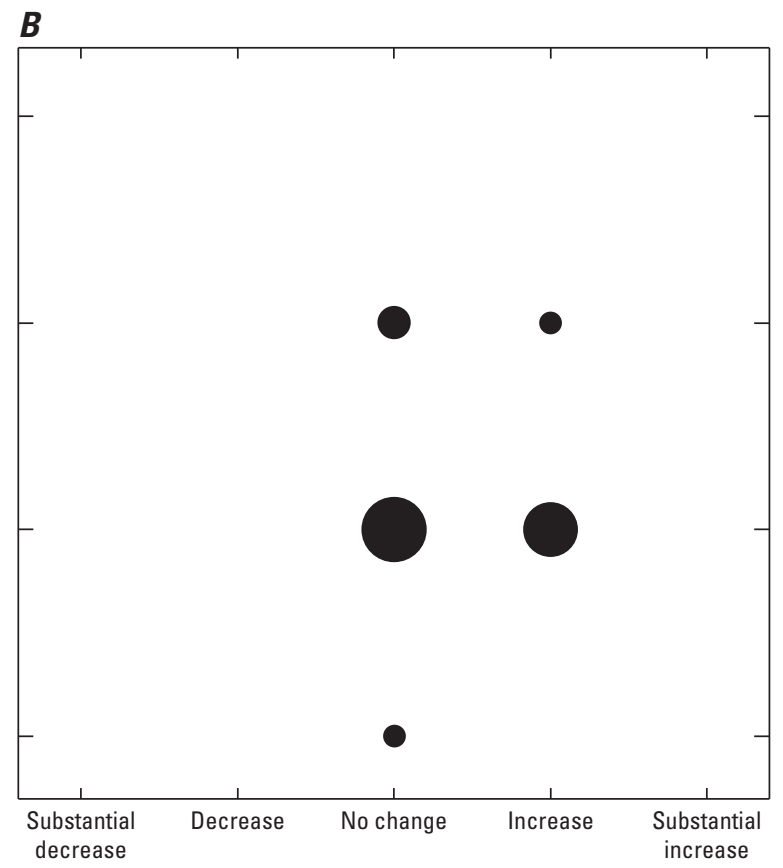

Figure 9. Answers and confidence associated with questions regarding potential benefits of backwaters $(A)$ and vegetated shorelines $(B)$ to native fish. Area of bubble is proportional to number of responses. These two questions had the lowest confidence scores in the survey. Respondents who view creation of backwaters as a potentially useful tool for benefitting native-fish populations are in the minority. 
mainstem. Whether that is enough to be measured in terms of abundance increase over several years time is unknown, but seems to be an expensive approach (in terms of power revenue) to achieve a tenuous goal."

"The idea that Colorado River native fishes commonly utilize and benefit from backwaters comes from the upper [Colorado River] basin where many backwaters are numerous acres in size. In contrast, Grand Canyon backwaters are more limited in size. Furthermore, the humpback chub populations in the upper basin continue to drastically decline despite the presence of large backwaters. The warmer temperatures in Grand Canyon backwaters are definitely a positive attribute, while the lack of cover is a negative attribute."

"We have no data to indicate backwaters by themselves are beneficial to native fish. If the backwater provides increased water temperatures or increased food or increased cover then they would likely be beneficial to native fish, but as of yet we have been unable to show that they provide these things."

"Until backwaters provide a large component of the available habitat for fish, I would say that the effects of backwaters to overall population levels is negligible. However, based on the question, if sizes of backwater habitat and the number of backwaters substantially changes then there may be an effect."

"It is difficult to say if fluctuating flows continue. The benefits of backwaters may be a stable, warmer environment for native fish rearing; however, fluctuating flows during the summer minimize the potential benefits. In addition, limited research into the use of backwaters, relative to other habitats, by native fish has been conducted."
Question 11: An increase in the size, distribution, and number of vegetated shorelines would cause a in native fish abundance.

Choices: Substantial Decrease, Decrease, No Change, Increase, Substantial Increase.

The distribution of responses to this question was similar to the related question on backwaters (fig. 9B; table 1), with most respondents ( 11 of 18 , or 61 percent) answering No Change as the most likely outcome of an increase in vegetated shorelines.

\section{Narratives}

"Young humpback chub in the [Little Colorado River] commonly utilize [vegetation] for cover. In the mainstem humpback chub do seem to be often captured along vegetated shorelines in the mainstem. I am not sure that enhancement of vegetated shoreline in the mainstem would increase the abundance of native fish in the mainstem, but it should be expected to provide some cover and perhaps some food."

"Vegetated shorelines do provide cover for small fish and reduce predation vulnerability."

"...there is much more vegetated shoreline habitat than backwaters, and because of this [an increase in] vegetated shorelines would have a greater effect [than an increase in backwaters]."

"The vegetative shorelines will provide an increase in terrestrial invertebrates for food, and high cover if the vegetation extends into the water column. However, juvenile native fish still need to grow to become less susceptible to piscivory."

"Hard to answer this without knowing what increase means." 
Question 12A: What will happen if a temperaturecontrol device is implemented? Native fish abundance will

Choices: Substantially Decrease, Decrease, Not Change, Increase, Substantially Increase.

Most respondents ( 13 of 18 , or 72 percent) answered an Increase in native fish abundance as the most likely outcome should a temperature control device be implemented on Glen Canyon Dam (fig. 10A; table 1). 4 of 18 respondents (22 percent) answered Substantial Increase, and 1 of 18 respondents (6 percent) answered Substantial Decrease, as the most likely outcome.

\section{Narratives}

"This is a tough question because I fear that nonnative fish will expand rapidly as well and they may have negative impacts on native fish. If nonnatives do not increase in abundance, then some improvement in native fish populations [is likely]."

"Given increasing [humpback chub] status, does not seem worth the risk!"

"As long as it is operated in a fashion to prevent the establishement and expansion of other warm-water nonnative fishes."

"Depends on nonnative fish population response and new species of invaders."

"Only so long as nonnatives do not increase more and wipe out the natives. Uncertainty lies there. If no nonnatives, then native fish would be much happier with a warmer river (in summer)"

"In the absence of any other treatment action, we will lose the native species in Grand Canyon. I am confident that there will be a large initial increase in native fish populations, especially if temperatures are warmed enough to kill off large numbers of trout. However, once the warmwater predators become established, the subsequent die-off of native fish will far surpass the boost provided by initial warming and will likely lead to their extirpation."

Question 12B: Are safeguards needed before a temperature control device can safely be operated?

13 of 15 respondents answered True (87 percent) while 2 of 15 (13 percent) answered False.

Narratives

"Lots of safeguards are needed."

"[There is a] need to not just have warm water, but warm and cold water both. The river is not just colder, but has lost the annual variability."

"I do not think that you can operate a temperature control device in a way that will benefit warmwater native species, yet not benefit warmwater nonnative species. The only option that I can see to even experiment with is to keep the mainstem cold during spawning and rearing season (spring and summer), when young humpback chub drift out of the LCR and into the mainstem. That is the only way you are going to keep nonnative warmwater piscivores from reproducing and taking over."

"Ability and willingness to [have] both hot and cold water years."

"Fish monitoring, followed by remedial actions if need be. A [temperature control device] should allow managers to quickly revert back to colder releases if need be." 
"Monitor for establishment of warm-water nonnative fish and develop action plan in the event this occurs."

"The biggest safeguard needed in my estimation is that we need the ability to control the TCD at least to the ability to run dam release temperatures between 10 and 16 [degrees Celsius]. Other safeguards

Question 12A: What will happen if a temperature control device is implemented? Native fish abundance will

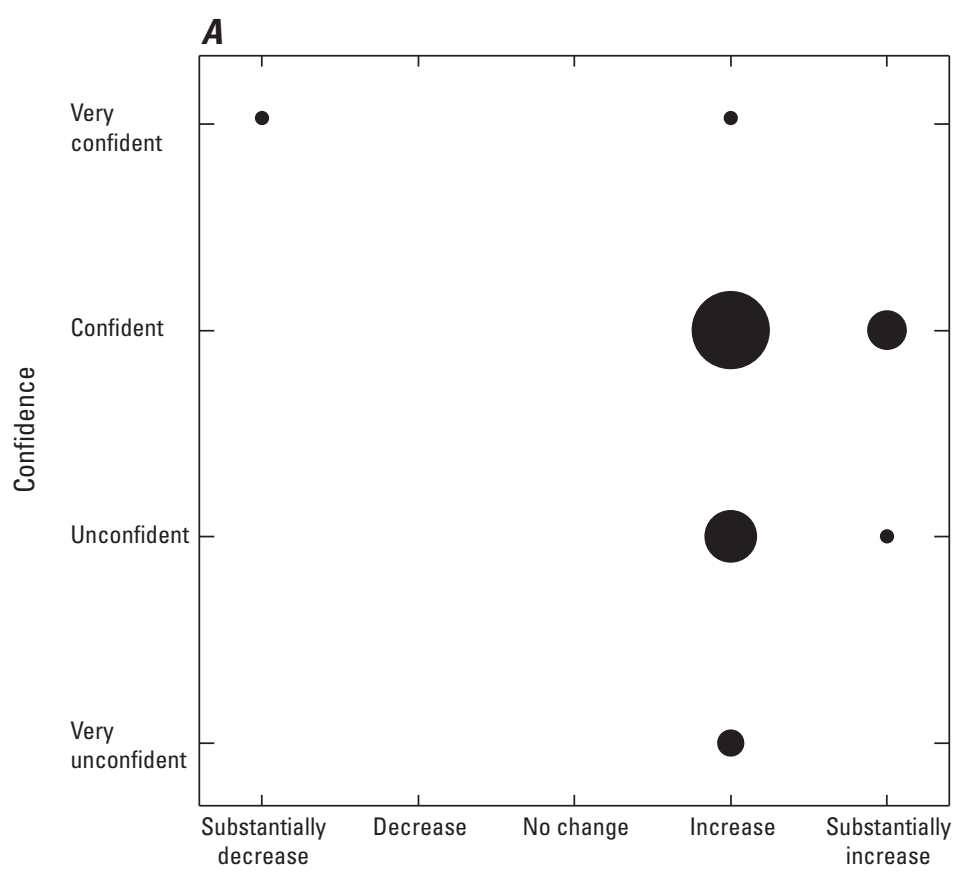

would be a [fish] monitoring regime, probably at near existing levels. Provided that managers do not increase water temperatures beyond that already experienced (about 16 [degrees Celsius]), or increase the duration of warmer water longer than already experienced, the invasion of other warm water predators may not be of great concern."

Question 12B: Are safeguards needed before a temperature control device can safely be operated?

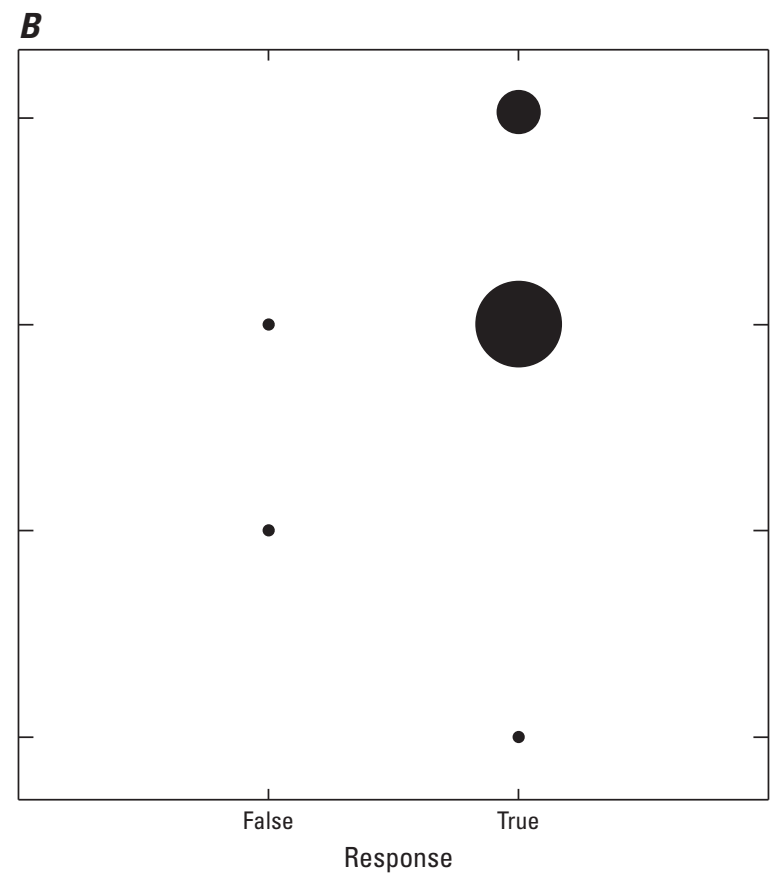

Figure 10. Answers and confidence associated with a question regarding native-fish response to implementation of a temperaturecontrol device on Glen Canyon Dam $(A)$, and the related true/false question asking whether safeguards are needed before a temperature control device can safely be operated $(B)$. Area of bubble is proportional to the number of responses. Most respondents believe that implementation of a temperature-control device will lead to an increase in native-fish populations; however, note that this question had a low confidence score $(0.53$, or about halfway between unconfident and confident). Furthermore, most respondents believe that safeguards (for example, effective nonnative control, a willingness to not use the temperature-control device in some years; see narratives) are needed before a temperature-control device can safely be implemented. 
Question 13: List up to three actions that you think should be taken because of their potential to benefit native-fish populations.

Nonnative control (17 of 20 respondents, or 85 percent) and installation of a temperature-control device (16 of 20 respondents, or 80 percent) were the most common actions recommended by respondents (fig. 11). Respondents also listed various types of humpback chub translocations (4 of 20 respondents, or 20 percent) and experimental flow regimes (7 of 20 respondents, or 35 percent) as actions that might be considered for benefiting native fish.

List up to 3 actions that you think should be taken because of their potential to benefit native fish populations.
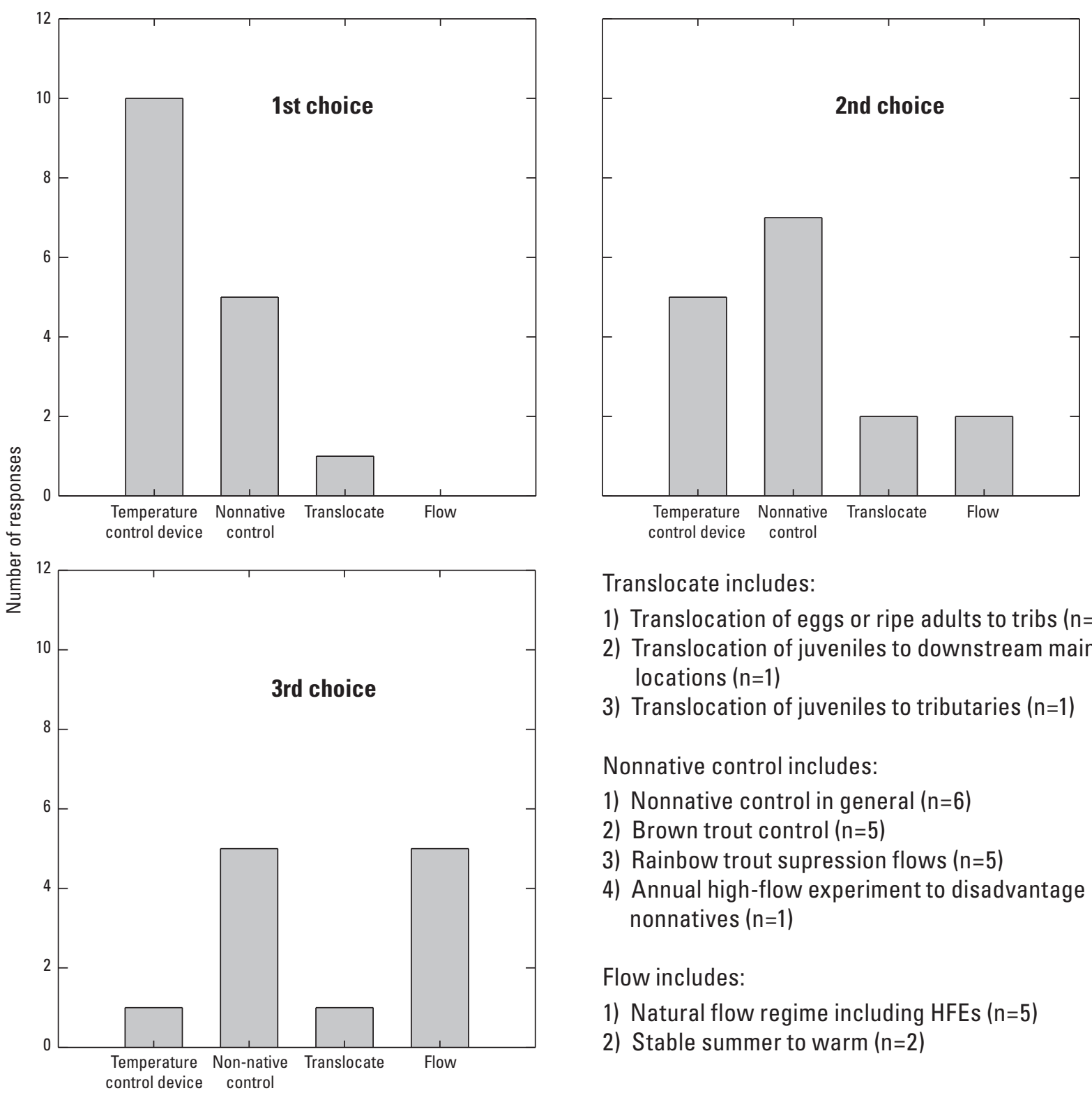

Translocate includes:

1) Translocation of eggs or ripe adults to tribs $(n=2)$

2) Translocation of juveniles to downstream mainstem locations $(n=1)$

3) Translocation of juveniles to tributaries $(n=1)$

Nonnative control includes:

1) Nonnative control in general $(n=6)$

2) Brown trout control $(n=5)$

3) Rainbow trout supression flows $(n=5)$

4) Annual high-flow experiment to disadvantage nonnatives $(n=1)$

Flow includes:

1) Natural flow regime including HFEs $(n=5)$

2) Stable summer to warm $(n=2)$

Figure 11. First, second, and third choice actions that respondents think should be conducted because of their potential to benefit native-fish populations. Installation of a temperature control device was listed as the first choice by 10 respondents and a total of 16 respondents included a temperature-control device somewhere on their list. Nonnative control in various forms was another common type of action listed by most respondents (17 of 20, or 85 percent). Translocation of humpback chub was listed as the first choice by one respondent, a total of four respondents listed translocations somewhere on their list. Seven respondents listed various types of flow-regime change as a management action that they think would benefit native fish. 


\section{Discussion}

Expert elicitation (the process of soliciting information from highly skilled and knowledgeable scientists) is increasingly being used as a tool to help managers make informed decisions when actual data on the system being managed are scarce, incomplete, or unavailable (Runge and others, 2011a). Formal expert elicitation involves asking experts independently to provide input on hypotheses or parameters of interest regarding the system being managed. Expert responses are then collated and presented to the whole group, along with the basis and rationale for each expert's decision. Experts are then given the opportunity to revise their answers on the basis of the insights from others in the group. These revised answers are then used as a tool to evaluate the various policy options being considered (Runge and others, 2011a).

The questionnaire results presented in this report do not represent a complete expert elicitation process. The strategic science questions presented here were discussed by all respondents several months before distribution of the questionnaire during the June 2011 Knowledge Assessment Workshop. These earlier discussions may have influenced or biased the answers that were given in the questionnaire. Furthermore, although questionnaire responses were collated and presented to the group during the October 2011 Knowledge Assessment Workshop, respondents were never given an opportunity to revise their answers. If respondents had been given an opportunity to revise their answers on the basis of insights from others in the group, some respondents would likely have changed some of their answers. For example, the two questions that had the highest confidence assessments also received nearly unanimous answers (see fig. 3 [Is the amount of invertebrate biomass/production available for consumption by fish affected by water-quality parameters such as temperature, nutrient concentrations, turbidity?] and fig. 4A [Do current water temperatures limit spawning and incubation success for native fish in the mainstem?]). In the case of the invertebrate question, studies throughout the world have documented a strong and clear link between invertebrate biomass/production and the waterquality parameters listed (see Huryn and Wallace, 2000, for a review). In the case of the temperature-fish spawning question, laboratory studies clearly demonstrate that current water temperatures limit spawning in the mainstem Colorado River (see Hamman, 1982). Responses to these two questions highlight the shortcomings of both the expert elicitation process in general (even "experts" sometimes get the answer wrong initially), and the abbreviated expert-elicitation exercise presented here (Responses presented here represent an initial assessment of complex issues from 20 scientists and have not been refined and revised on the basis of insights from others in the group). With this qualifier in mind, what follows is a discussion of questionnaire responses regarding three issues that are of continuing interest to the Glen Canyon Dam Adaptive Management Program: effects of water temperature on native fish, effects of nonnative trout on native fish, and use of high-flow experiments as a tool for managing native-fish populations.

\section{Water Temperature}

There is strong consensus among respondents that cold water temperatures are playing a role in limiting native-fish populations in Grand Canyon (see figs. 4, 10, 11). On an openended question (fig. 11), 10 of 20 respondents (50 percent) listed implementation of a temperature-control device as the first management action they would conduct because of potential benefits to native fish. The question with the second highest confidence score in the survey (ig. 4) was temperature related: Do current water temperatures limit spawning and incubation success for native fish in the mainstem? 18 of 20 respondents (90 percent) answered True to this question, and the certainty score - 0.76 - places it between confident and very confident. But when asked the question of how nativefish populations would actually respond to implementation of a temperature-control device in an ordinal question (fig. 10A), respondents expressed concerns over potential increases in warm-water nonnative species in basically every narrative, leading to a low confidence score on this question $(0.53$, or approximately halfway between unconfident and confident). Most respondents listed an Increase in native fish populations as the likely outcome, should a temperature-control device be implemented (13 of 18 , or 72 percent), and 4 of 18 respondents (22 percent) listed a Substantial Increase in native-fish populations as the likely outcome. One respondent listed a Substantial Decrease in native-fish populations as the most likely outcome, with an associated assessment of Very Confident. Most respondents-13 out of 15 (87 percent)believe that safeguards, especially programs for monitoring and controlling nonnative species, are needed before a temperature-control device can safely be implemented (fig. 10B).

Water temperature is clearly a double-edged sword for native fish in Grand Canyon. Implementation of a temperaturecontrol device on Glen Canyon Dam could greatly benefit native-fish populations by increasing growth and survival rates (Petersen and Paukert, 2005) and providing water temperatures conducive to mainstem spawning. However, warmer water temperatures might also allow warm-water nonnative species (for example, smallmouth bass, northern pike, channel catfish) to become established in Grand Canyon (currently, populations of these warm-water nonnatives are extremely low or nonexistent). Predation by warm-water 
nonnative species is a primary factor driving native-fish decreases in the upper Colorado River basin (see Bestgen and others, 2007). If warm-water nonnatives become established at high densities in Grand Canyon because of implementation of a temperature-control device, negative impacts of predation on native species would likely far outweigh any intended benefits to native fish (for example, improvements in growth and spawning). If managers are interested in more detailed predictions regarding native and nonnative-fish response to implementation of a temperature-control device, a full and interative expert elicitation process is a logical next step.

\section{Nonnatives}

Most respondents ( 16 of 19 , or 84 percent) believe there is sufficient evidence to conclude that when populations of nonnative rainbow trout are large, they limit abundance of adult humpback chub populations (fig. 1A). Interestingly, a larger number of respondents ( 19 of 20 , or 95 percent) believe there is sufficient evidence to conclude that when brown trout populations are large they limit the abundance of adult humpback chub (fig. 1B). The confidence score for the brown trout question $\left(6^{\text {th }}\right)$ also was ranked higher than the rainbow trout question $\left(11^{\text {th }}\right)$. Note, however, that both confidence scores are low, falling between unconfident and confident. Respondents answers and the confidence on these trout questions were qualitatively similar to those of the answers provided as part of a nonnative-fish-control structureddecisionmaking process (Runge and others, 2011b).

Respondents' answers to these questions about the relative threat of these two nonnative salmonids were likely informed by the findings of Yard and others (2011), who documented that brown trout in Grand Canyon are extremely piscivorous (5-70 percent of brown trout stomachs analyzed contained fish remains, depending on season and location), whereas rainbow trout were less piscivorous ( $0.5-3.3$ percent of rainbow trout stomachs analyzed contained fish remains). Rainbow trout were 50 times more abundant in the study area of Yard and others (2011) relative to brown trout, leading these investigators to conclude that rainbow trout piscivory was actually a greater source of mortality for native fish relative to piscivory by brown trout. Although predation by both rainbow trout and brown trout was a large source of mortality to native fish in general and humpback chub specifically (for example, during 2003-04, rainbow trout preyed upon more than 2,500 individual humpback chub per year and brown trout preyed upon more than 1,500 individual humpback chub per year), Yard and others (2011) cautioned that their study did not provide proof that rainbow or brown trout piscivory was having a population-level effect on humpback chub. Thus, Yard and others (2011) demonstrated that individual humpback chub were vulnerable to trout predation, but the population as a whole might be constrained by other factors, such that the mortality imposed by trout has only a minor effect on overall humpback chub population abundance.
Brown trout control seems like a logical focus for nonnative-fish management in Grand Canyon National Park, given scientists' views on the threat that brown trout pose to humpback chub populations. Brown trout populations are considerably smaller than rainbow trout populations (Makinster and others, 2010). Furthermore, most brown trout spawning in Grand Canyon is restricted to a single tributaryBright Angel Creek - whereas rainbow trout spawning occurs throughout the 16-mi Glen Canyon tailwater reach (Makinster and others, 2010). Both of these factors make controlling brown trout using mechanical removal cheaper and more feasible logistically than mechanically removing rainbow trout.

Limiting the abundance of rainbow trout populations near the Little Colorado River confluence also is consistent with scientists' views and available data (see Yard and others, 2011) on the threat that rainbow trout pose to endangered humpback chub populations; however, mechanical removal of rainbow trout may be ineffective when rainbow trout populations are increasing (Coggins and others, 2011). Alternative rainbow trout control strategies involving experimental flows will be evaluated as part of ongoing adaptive-management experimentation (Bureau of Reclamation, 2011). If these new strategies are effective at controlling rainbow trout, have a low cost of control, and have minimal or acceptable impacts on other resources (for example, aquatic food base), then resolving the uncertainty about whether rainbow trout are actually having a population-level effect on humpback chub may be unnecessary (Runge and others, 2011b). In contrast, if these new strategies for controlling rainbow trout are ineffective and excessively costly, result in negative impacts to other resources, and become unacceptable to managers, then resolving the uncertainty regarding population-level effects of rainbow trout on humpback chub may be necessary (Runge and others, 2011b).

\section{High-Flow Experiments}

Most respondents do not view high-flow experiments as a useful tool for managing native-fish populations (see figs. 8; $\underline{9 A}$ ). It has been hypothesized that high-flow experiments could benefit native fish by displacing nonnative species (U.S. Department of the Interior, 1995). Nonnative species are more likely to be displaced during extreme flood events, whereas native species exhibit various behavioral adaptations that make them less susceptible to displacement (Ward and others, 2003); however, long-term monitoring failed to document substantial declines in nonnative fish abundance after high-flow experiments in 2004 and 2008 (Makinster and others, 2010). Recent observations that the 2008 high-flow experiment actually led to significant increases in nonnative rainbow trout populations (Cross and others, 2011; Korman and others, 2011) also call into question the validity of this hypothesis. These recent results likely influenced scientists' responses to a question regarding the effect of high-flow experiments 
on nonnative predation (fig. 8). This question had a low confidence score (rank of 14 out of 16) and no single answer received a majority of responses. Five respondents believe that frequent high-flow experiments will Somewhat Increase Predation by nonnatives, and five respondents believe that there will be No Change in predation by nonnatives if frequent high-flow experiments occur (fig. 8). Thus, there is little support from the questionnaire respondents or from available data to suggest that high-flow experiments of the magnitude, duration, or frequency previously evaluated actually benefited native fish through displacement of nonnatives.

A second hypothesis regarding effects of high-flow experiments on native fish posits that the creation of backwaters will benefit juvenile native fish by providing highquality rearing areas (U.S. Department of the Interior, 1995).

Backwaters have been viewed as high-quality rearing areas for juvenile native fish because of the warm-water temperatures that can sometimes occur. Recent research indicates that increases in backwater area and number following high-flow experiments are extremely transitory and short-lived when discharge fluctuates owing to hydropeaking (that is, increases in backwater area due to the 2008 high-flow experiment lasted less than 6 months; Grams and others, 2010). Furthermore, daily fluctuations in river stage associated with hydropeaking causes frequent flushing of backwaters (Behn and others, 2010), which limits the amount of warming that can occur in these areas. These recent findings likely informed respondents' answers to an ordinal question regarding potential nativefish response to an increase in backwaters (see fig. 9) - 11 of 19 respondents (58 percent) answered that No Change in native-fish abundance was the most likely outcome of an increase in backwaters. Several of the narratives associated with this question noted that fluctuating flows quickly erode backwaters and limit the amount of warming that can occur during the summer. Other narratives noted that backwaters are a small proportion of shoreline habitat in Grand Canyon, even immediately following a high-flow experiment. Thus, there is little support from questionnaire respondents or from available data to suggest high-flow experiments benefit native fish through backwater creation, particularly if daily fluctuations in discharge associated with hydropeaking immediately follow a high-flow experiment.

\section{Acknowledgments}

I thank the 20 scientists and managers who responded to this questionnaire, particularly for their thoughtful and insightful narratives. I thank David Ward and Jack Schmidt for providing informative and helpful feedback on a draft of the questionnaire, and Charles Yackulic for discussions and advice regarding the graphical and statistical presentation of these data. David Ward, Brian Healy, Dennis Stone, Scott Vanderkooi, Jeff Lovich, Charles Yackulic, Ted Melis, and Jack Schmidt provided constructive criticism in their reviews of the draft manuscript of this report.

\section{References Cited}

Behn, K.E., Kennedy, T.A., and Hall, R.O., Jr., 2010, Basal resources in backwaters of the Colorado River below Glen Canyon Dam-Effects of discharge regimes and comparison with mainstem depositional environments: U.S. Geological Survey Open-File Report 2010-1075, 25 p., accessed July 24, 2010, at http://pubs.usgs.gov/ of/2010/1075/of2010-1075.pdf.

Bestgen, K.R., Zelasko, K.A., and Wilcox, C.T., 2007, Non-native fish removal in the Green River, Lodore and Whirlpool Canyons, 2002-2006, and fish community response to altered flow and temperature regimes, and non-native fish expansion: Colorado River Recovery Implementation Program project number 115, Larval Fish Laboratory contribution 149, submitted to Colorado State University, Fort Collins, 84 p.

Bureau of Reclamation, 2011, Environmental assessmentNon-native fish control downstream from Glen Canyon Dam: Salt Lake City, Utah, Bureau of Reclamation, Upper Colorado Region, 102 p. + appendices, accessed on March 21, 2012, at http://www.usbr.gov/uc/envdocs/ea/gc/ nnfc/NNFC-EA.pdf.

Carpenter, S.R., Folke, C., Scheffer, M., and Westley, F.R, 2009, Resilience-Accounting for the noncomputable: Ecology and Society, v. 14, no. 1, art. 13. (Also available at http://www.ecologyandsociety.org/vol14/iss1/art13/.)

Coggins, L.G., Yard, M.D., and Pine, W.E., 2011, Nonnative fish control in the Colorado River in Grand Canyon, Arizona-An effective program or serendipitous timing?: Transactions of the American Fisheries Society, v. 140, no. 2, p. 456-470, doi: 10.1080/00028487.2011.572009, accessed July 29, 2011, at http://www.tandfonline.com/doi/ abs/10.1080/00028487.2011.572009.

Cross, W.F., Baxter, C.V., Donner, K.C., Rosi-Marshall, E.J., Kennedy, T.A., Hall, R.O., Jr., Wellard-Kelly, H.A., and Rogers, R.S., 2011, Ecosystem ecology meets adaptive management-Food web response to a controlled flood on the Colorado River, Glen Canyon: Ecological Applications, v. 21, no. 6, doi: 10.1890/10-1719.1, p. 2016-2033, accessed June 28, 2011, at http://www.esajournals.org/doi/ abs/10.1890/10-1719.1.

Grams, P.E., Schmidt, J.C., and Andersen, M.E., 2010, 2008 High-flow experiment at Glen Canyon Dam-Morphologic response of eddy-deposited sandbars and associated aquatic backwater habitats along the Colorado River in Grand Canyon National Park: U.S. Geological Survey Open-File Report 2010-1032, 73 p., accessed July 27, 2010, at http:// pubs.usgs.gov/of/2010/1032/. 
Hamman, R.L., 1982, Spawning and culture of humpback chub: The Progressive Fish-Culturist, v. 44, no. 4, p. 213216, accessed December 1, 2010, at http://www.tandfonline. com/doi/abs/10.1577/1548-8659\%281982\%2944\%5B213\% 3ASACOHC $\% 5$ D2.0.CO $\% 3 \mathrm{~B} 2$.

Huryn, A.D., and Wallace, J.B., 2000, Life history and production of stream insects: Annual Review of Entomology, v. 45, doi: 10.1146/annurev.ento.45.1.83, p. 83-110, accessed April 18, 2011, at http://coweeta.uga. edu/publications/1436.pdf.

Korman, J., Kaplinski, M., and Melis, T.S., 2011, Effects of fluctuating flows and a controlled flood on incubation success and early survival rates and growth of age- 0 rainbow trout in a large regulated river: Transactions of the American Fisheries Society, v. 140, no. 2, p. 487-505, doi: 10.1080/00028487.2011.572015, accessed April 19, 2011, at http://www.tandfonline.com/doi/abs/10.1080/00028487.2 011.572015 .

Makinster, A.S., Persons, W.R., Avery, L.A., and Bunch, A.J., 2010, Colorado River fish monitoring in Grand Canyon, Arizona-2000 to 2009 summary: U.S. Geological Survey Open-File Report 2010-1246, 26 p., accessed November 5, 2010, at http://pubs.usgs.gov/of/2010/1246/.

Petersen, J.H., and Paukert, C.P., 2005, Development of a bioenergetics model for humpback chub and evaluation of water temperature changes in the Grand Canyon, Colorado River: Transactions of the American Fisheries Society, v. 134, no. 4, p. 960-974, doi: 10.1577/T04-090.1, accessed August 24, 2011, at http://www.tandfonline.com/doi/ abs/10.1577/T04-090.1.
Runge, M.C., Bean, Ellen, Smith, D.R., and Kokos, Sonja, 2011b, Non-native fish control below Glen Canyon DamReport from a structured decision-making project: U.S. Geological Survey Open-File Report 2011-1012, 74 p., at http://pubs.usgs.gov/of/2011/1012/.

Runge, M.C., Converse, S.J,, and Lyons, J.E., 2011a, Which uncertainty? Using expert elicitation and expected value of information to design an adaptive program: Biological Conservation, v. 144, no. 4, p. 1214-1223, doi:10.1016/j. biocon.2010.12.020, accessed June 1, 2012, at http://www. sciencedirect.com/science/article/pii/S000632071000529X.

U.S. Department of the Interior, 1995, Operation of Glen Canyon Dam-Final environmental impact statement, Colorado River storage project, Coconino County, Arizona: Salt Lake City, Utah, Bureau of Reclamation, Upper Colorado Regional Office, 337 p., accessed November 18, 2010, at http://www.usbr.gov/uc/library/envdocs/eis/gc/ pdfs/Cov-con/cov-con.pdf.

Walters, C.J., 1986, Adaptive management of renewable resources: New York, MacMillan Publishing Company, $374 \mathrm{p}$.

Ward, D.L., Shultz, A.A., and Matson, P.G.,2003, Differences in swimming ability and behavior in response to high water velocities among native and nonnative fishes: Environmental Biology of Fishes, v. 68, p. 87-92.

Yard, M.D., Coggins, L.G., Baxter, C.V., Bennett, G.E., and Korman, J., 2011, Trout piscivory in the Colorado River, Grand Canyon-Effects of turbidity, temperature, and fish prey availability: Transactions of the American Fisheries Society, v. 140, no. 2, p. 471-486, doi: 10.1080/00028487.2011.572011, accessed on April 19, 2011, at http://www.tandfonline.com/doi/abs/10.1080/00028 $\underline{487.2011 .572011 .}$. 


\section{Appendix 1. Knowledge Assessment Workshop Questionnaire}

Blank questionnaire that was distributed to scientists.

\section{Knowledge Assessment Workshop Questionnaire}

Questionnaire completed by:

Background information: As part of a knowledge assessment workshop being convened by the Grand Canyon Monitoring and Research Center (GCMRC) October 18-19, 2011, GCMRC is summarizing the state of our understanding of the aquatic ecosystem of the Colorado River downstream from Glen Canyon Dam, including our present understanding of the biotic and abiotic factors most likely affecting populations of native and nonnative fishes.

During the previous round of knowledge assessment workshops, in 2007, a set of strategic science questions was developed as a framework for focusing the research and monitoring activities conducted by GCMRC. These questions were originally developed as a collaboration of scientists and managers. As such, the questions that originated 5 years ago are not necessarily similar to those that might be developed in a proposal to the National Science Foundation. Also, all the questions are not necessarily of equal importance or merit - some questions are large-scale and others are of small-scale. Nevertheless, these questions were adopted and partly drive the mission of the GCMRC research program.

This questionnaire summarizes all of the major strategic science questions that have formed the basis for research and monitoring projects conducted since that 2007 workshop. These science questions have been reworded to make them more categorical, and hopefully easier to compile as we strive to summarize the state of scientific understanding. We have also included a section for you to score the level of confidence you have in your answer. A crosswalk that shows the original strategic science question and the associated, but reworded, questions in this questionnaire is included as an appendix 2. Several strategic science questions are not addressed in this questionnaire - these are also noted in appendix 2, including the basis for their omission.

As a scientist that has been involved in Colorado River research and monitoring, your answers to this questionnaire are of great interest to GCMRC. Your answers will be compiled in anonymous summary statistics to identify areas where there is consensus among the science community, and where there is still uncertainty and disagreement. Your name will be reported in a list of science experts that were surveyed.

We have provided a 'Notes' section at the end of each question. Please feel free to use this space to comment on any questions that you think are inherently intractable, and/or to qualify your answer or describe any assumptions you made in arriving at your answer. Please also feel free to leave any questions blank if you do not feel qualified to answer. 


\section{Questionnaire}

1. Why are the humpback chub not thriving, and what can we do about it?

List in order of importance three factors that you think presently limit humpback chub adult abundance, and then briefly describe an action that could be taken to mitigate this.

1.

2.

3.

Confidence in your answer:

Very Unconfident

Unconfident

Confident

Very Confident

Notes:

2. To what extent are adult populations of native fish controlled by (rank from 1 to 4 in order of importance, 1 being of greatest importance):

Production of young fish from tributaries

Spawning and incubation in the mainstem

Survival of young-of-year (YOY) and juvenile stages in the mainstem

Changes in growth and maturation in the adult population as influenced by mainstem conditions

Confidence in your answer:

Very Unconfident

Unconfident

Confident

Very Confident

Notes:

A) If rainbow trout populations were large, a decrease in their abundance would lead to improvements in recruitment of juvenile humpback chub to the adult population (true or false)

Confidence in your answer:

Very Unconfident

Unconfident

Confident

Very Confident

Notes: 
B) If brown trout populations were large, a decrease in their abundance would lead to improvements in recruitment of juvenile humpback chub to the adult population (true or false)

Confidence in your answer:

Very Unconfident

Unconfident

Confident

Very Confident

Notes:

C) If populations of small-bodied warm water non-natives (i.e., fathead minnow, red shiner, etc.) were large, a decrease in their abundance would lead to improvements in recruitment of juvenile humpback chub to the adult population (true or false)

Confidence in your answer:

Very Unconfident

Unconfident

Confident

Very Confident

Notes:

D) If populations of large-bodied warm water non-natives (i.e., channel catfish, common carp, etc.) were large, a decrease in their abundance would lead to improvements in recruitment of juvenile humpback chub to the adult population (true or false)

Confidence in your answer:

Very Unconfident

Unconfident

Confident

Very Confident

Notes:

4. To what extent do rainbow trout migrating from Glen Canyon support the population of rainbow trout in Marble and eastern Grand Canyon? (select one)

Migration from Glen Canyon does not support populations in Marble and Grand Canyon

Migration from Glen Canyon partially supports populations in Marble and Grand Canyon

Migration from Glen Canyon largely supports populations in Marble and Grand Canyon

Migration from Glen Canyon completely supports populations in Marble and Grand Canyon

Confidence in your answer:

Very Unconfident

Unconfident

Confident

Very Confident

Notes: 
5. What are the important pathways that link lower trophic levels with fish?

(Rank from 1 to 6 in order of importance, 1 being of greatest importance)

Algae-> invertebrates->fish

Detritus->invertebrates->fish

Terrestrial invertebrates->fish

Prey fish->predatory fish

algae->fish

detritus->fish

Confidence in your answer:

Very Unconfident

Unconfident

Confident

Very Confident

Notes:

6. Are trends in the abundance of fish populations or indicators from fish such as growth, condition, and body composition (for example, lipids), correlated with patterns in invertebrate flux? In other words, are fish food limited? (true or false)

Confidence in your answer:

Very Unconfident

Unconfident

Confident

Very Confident

Notes:

7. Which mainstem habitats are most important to native fishes? (rank from 1 to 5 in order of importance, 1 being of greatest importance)

Habitat types

Talus

Backwaters

Cliff

Cobble

Vegetated shoreline

Confidence in your answer:

Very Unconfident

Unconfident

Confident

Very Confident

Notes: 
8. To what extent could predation impacts by nonnative fish be mitigated by higher turbidities? (select one)

Higher turbidity would greatly increase predation impacts by nonnatives

Higher turbidity would somewhat increase predation impacts by nonnatives

Higher turbidity would have no impact on predation by nonnatives

Higher turbidities would somewhat reduce predation impacts by nonnatives

Higher turbidities would greatly reduce predation impacts by nonnatives

Confidence in your answer:

Very Unconfident

Unconfident

Confident

Very Confident

Notes:

9. To what extent could predation impacts by nonnative fish be mitigated by dam-controlled high-flow releases? (select one)

Frequent artificial floods would greatly increase predation by nonnatives

Frequent artificial floods would somewhat increase predation by nonnatives

Frequent artificial floods would have no impact on predation by nonnatives

Frequent artificial floods would somewhat reduce predation by nonnatives

Frequent artificial floods would greatly reduce predation by nonnatives

Confidence in your answer:

Very Unconfident

Unconfident

Confident

Very Confident

Notes:

10. Is the amount of invertebrate biomass/production available for consumption by fish affected by water quality parameters (e.g., temperature, nutrient concentrations, turbidity)? (True or false)

Confidence in your answer:

Very Unconfident

Unconfident

Confident

Very Confident

Notes: 
11. An increase in the size, distribution, and number of backwaters would cause (select one):

A substantial decrease in native fish abundance

A decrease in native fish abundance

No change in native fish abundance

An increase in native fish abundance

A substantial increase in native fish abundance

Confidence in your answer:

Very Unconfident

Unconfident

Confident

Very Confident

Notes:

12. An increase in the size, distribution, and number of vegetated shorelines would cause (select one):

A substantial decrease in native fish abundance

A decrease in native fish abundance

No change in native fish abundance

An increase in native fish abundance

A substantial increase in native fish abundance

Confidence in your answer:

Very Unconfident

Unconfident

Confident

Very Confident

Notes:

13. What are the most important aspects of high-quality juvenile native fish rearing habitat? (rank from 1 to 4,1 being of greatest importance)

Water temperatures

Cover

Low energy/slow water velocities

Food availability

Confidence in your answer:

Very Unconfident

Unconfident

Confident

Very Confident

Notes: 
14. What will happen if a temperature control device is implemented? (select one)

Native fish abundance will substantially decrease

Native fish abundance will decrease

Native fish abundance will not change

Native fish abundance will increase

Native fish abundance will substantially increase

Confidence in your answer:

Very Unconfident

Unconfident

Confident

Very Confident

Notes:

15. Are safeguards needed before a temperature control device can safely be operated? (True or false)

Confidence in your answer:

Very Unconfident

Unconfident

Confident

Very Confident

If above is true, list potential safeguards

Notes:

16. Do current water temperatures limit spawning and incubation success for native fish in the mainstem? (True or false)

Confidence in your answer:

Very Unconfident

Unconfident

Confident

Very Confident

Notes: 
17. Do current flow fluctuations allowed by the Record of Decision (i.e., MLFF) limit spawning and incubation success for native fish in the mainstem? (True or false)

Confidence in your answer:

Very Unconfident

Unconfident

Confident

Very Confident

Notes:

18. What is the relative importance of increased water temperatures, shoreline stability, and food availability on the survival and growth of YoY and juvenile native fish? (Score each: 1 = unimportant, 2 = somewhat important, $3=$ important, 4 = very important)

Water temperatures

Shoreline stability

Food availability

Confidence in your answer:

Very Unconfident

Unconfident

Confident

Very Confident

Notes:

19. Do the potential benefits of improving juvenile native fish rearing habitat in the mainstem (e.g., increasing water temperatures with a TCD, stabilizing flows, conducting frequent HFEs to increase the number of backwaters and vegetated shorelines, increasing food availability) outweigh negative impacts due to increases in nonnative fish abundance? (true/false)

Confidence in your answer:

Very Unconfident

Unconfident

Confident

Very Confident

Notes:

20. List up to 3 actions that you think should be taken because of their potential to benefit native fish populations. 


\section{Appendix 2. Crosswalk between Original Strategic Science Questions (SSOs) and This Questionnaire}

AMWG Priority 1: Why are the humpback chub not thriving, and what can we do about it? How many humpback chub are there and how are they doing? (GCDAMP Goal 2)

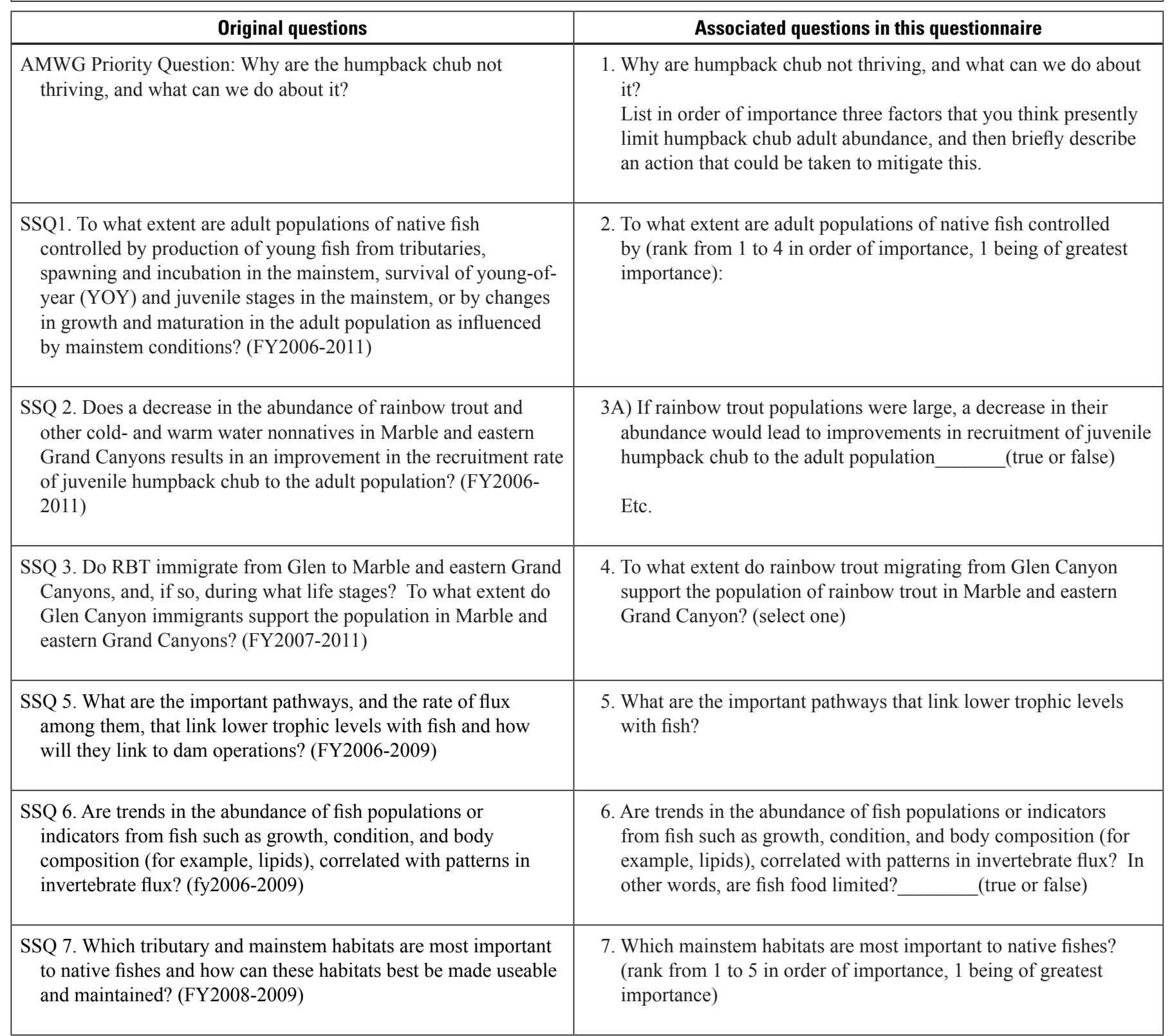

AMWG Priority 3 : What is the best flow regime?

SSQ 2. To what extent could predation impacts by nonnative fish be mitigated by higher turbidities or dam-controlled high-flow releases? (FY2007-2008)

SSQ 5. How is invertebrate flux affected by water quality (for example, temperature, nutrient concentrations, turbidity) and dam operations? (FY2006-2008)
8. To what extent could predation impacts by nonnative fish be mitigated by higher turbidities? (select one)

9. To what extent could predation impacts by nonnative fish be mitigated by dam-controlled high-flow releases? (select one)

10. Is the amount of invertebrate biomass/production available for consumption by fish affected by water quality parameters (e.g., temperature, nutrient concentrations, turbidity)? false) (True or 
AMWG Priority 4: What is the impact of sediment loss and what should we do about it? (GCDAMP goal 8)

\begin{tabular}{|c|c|}
\hline \multicolumn{1}{|c|}{ Original questions } & \multicolumn{1}{c|}{ Associated questions in this questionnaire } \\
\hline $\begin{array}{l}\text { SSQ 2. How important are backwater and vegetated shoreline } \\
\text { habitats to the overall growth and survival of YoY and juvenile } \\
\text { native fish? Does the long-term benefit of increasing these } \\
\text { habitats outweigh short-term potential costs (displacement and } \\
\text { possibly mortality of young humpback chub) associated with } \\
\text { high flows? (FY2007-2011) }\end{array}$ & $\begin{array}{c}\text { 11. An increase in the size, distribution, and number of backwaters } \\
\text { would cause (select one): }\end{array}$ \\
$\begin{array}{l}\text { 12. An increase in the size, distribution, and number of vegetated } \\
\text { shorelines would cause (select one): }\end{array}$ \\
$\begin{array}{l}\text { 13. What are the most important aspects of high-quality juvenile } \\
\text { native fish rearing habitat? (rank from 1 to 5, 1 being of greatest } \\
\text { importance) }\end{array}$ \\
\hline
\end{tabular}

AMWG priority 5: What will happen when we test or implement the temperature control device (TCD)? How should it be operated? Are safeguards needed for management? (GCDAMP goals 1-4 and 7-10)

\begin{tabular}{|c|c|}
\hline $\begin{array}{l}\text { AMWG Priority } 5 \text {. What will happen when we test or implement } \\
\text { the temperature control device (TCD)? }\end{array}$ & $\begin{array}{l}\text { 14. What will happen if a temperature control device is } \\
\text { implemented? (select one) }\end{array}$ \\
\hline $\begin{array}{l}\text { SSQ 3. To what extent do temperature and fluctuations in flow limit } \\
\text { spawning and incubation success for native fish? (FY2003-2008) }\end{array}$ & $\begin{array}{l}\text { 16. Do water temperatures limit spawning and incubation success } \\
\text { for native fish in the mainstem? } \\
\text { (True or false) } \\
\text { 17. Do flow fluctuations limit spawning and incubation success for } \\
\text { native fish in the mainstem? } \\
\text { (True or false) }\end{array}$ \\
\hline $\begin{array}{l}\text { SSQ 4. What is the relative importance of increased water } \\
\text { temperatures, shoreline stability, and food availability on the } \\
\text { survival and growth of YoY and juvenile native fish? (FY2003- } \\
\text { 2008) }\end{array}$ & $\begin{array}{l}\text { 18. What is the relative importance of increased water temperatures, } \\
\text { shoreline stability, and food availability on the survival and } \\
\text { growth of YoY and juvenile native fish? (Score each: } 1= \\
\text { unimportant, } 2 \text { = somewhat important, } 3=\text { important, } 4=\text { very } \\
\text { important) }\end{array}$ \\
\hline $\begin{array}{l}\text { SSQ 6. Do the potential benefits of improved rearing habitat } \\
\text { (warmer, more stable, more backwater and vegetated shorelines, } \\
\text { more food) outweigh negative impacts due to increases in } \\
\text { nonnative fish abundance? (FY2007-2011) }\end{array}$ & $\begin{array}{l}\text { 19. Do the potential benefits of improving juvenile native } \\
\text { fish rearing habitat in the mainstem (e.g., increasing water } \\
\text { temperatures with a TCD, stabilizing flows, conducting } \\
\text { frequent HFEs to increase the number of backwaters } \\
\text { and vegetated shorelines, increasing food availability) } \\
\text { outweigh negative impacts due to increases in nonnative fish } \\
\text { abundance? } \\
\text { (true/false) }\end{array}$ \\
\hline
\end{tabular}




\section{SSOs that do not have an associated question in this questionnaire:}

AMWG Priority 1, SSQ 4. Can long-term decreases in abundance of RBT in Marble and eastern Grand Canyons be sustained with a reduced level of effort of mechanical removal or will recolonization from tributaries and from downstream and upstream of the removal reach require that mechanical removal be an ongoing management action? This question also applies to future removal programs targeting other nonnative species. (FY2007-2011)

Reason not included: question is too open-ended and leading. A target abundance for rainbow trout is not specified, which makes it impossible to answer the question. The question assumes RBT abundance at the LCR needs to be minimized-this issue of RBT impacts is the subject of numerous other SSQs.

AMWG Priority 1, SSQ 8. How can native and nonnative fish best be monitored while minimizing impacts from capture and handling or sampling? (FY2007-2011)

Reason not included: This was addressed by the 2009 PEP.

AMWG Priority 5, SSQ 2. How is invertebrate flux affected by water quality (for example, temperature, nutrient concentrations, turbidity) and dam operations? (FY2006-2008)

Reason not included: This question is redundant with earlier questions.

AMWG Priority 5, SSQ 5. Will increased water temperatures increase the incidence of Asian tapeworm in humpback chub or the magnitude of infestations, and if so, what is the impact on survival and growth rates? (FY2003-2008)

Reason not included: There are no data available on the impact of tapeworm loads on survival and growth of HBC. 
This page left intentionally blank 
Publishing support provided by the U.S. Geological Survey

Publishing Network, Menlo Park and Tacoma Publishing Service Centers

For more information concerning the research in this report, contact the Director, Southwest Biological Science Center

U.S. Geological Survey

2255 N. Gemini Drive

Flagstaff, Arizona 86001

http://sbsc.wr.usgs.gov/ 
